Effects of muscular dystrophy, exercise and blocking activin receptor IIB ligands on the unfolded protein response and oxidative stress

\author{
Hulmi, Juha J.
}

2016-10

Hulmi , J J , Hentila , J , DeRuisseau , K C , Oliveira , B M , Papaioannou , K G , Autio , R , Kujala , U M , Ritvos , O , Kainulainen , H , Korkmaz , A \& Atalay , M 2016 , ' Effects of muscular dystrophy, exercise and blocking activin receptor IIB ligands on the unfolded protein response and oxidative stress ' , Free Radical Biology \& Medicine , vol. 99 , pp. 308-322 . https://doi.org/10.1016/j.freeradbiomed.2016.08.017

http://hdl.handle.net/10138/229645

https://doi.org/10.1016/j.freeradbiomed.2016.08.017

publishedVersion

Downloaded from Helda, University of Helsinki institutional repository.

This is an electronic reprint of the original article.

This reprint may differ from the original in pagination and typographic detail.

Please cite the original version. 
Original article

\title{
Effects of muscular dystrophy, exercise and blocking activin receptor IIB ligands on the unfolded protein response and oxidative stress
}

\author{
Juha J. Hulmi a,b,*, Jaakko Hentilä ${ }^{\text {a }}$, Keith C. DeRuisseau ${ }^{\mathrm{c}, \mathrm{d}}$, Bernardo M. Oliveira ${ }^{\mathrm{a}, 1}$, \\ Konstantinos G. Papaioannou ${ }^{\mathrm{a}}$, Reija Autio ${ }^{\mathrm{e}}$, Urho M. Kujala ${ }^{\mathrm{f}}$, Olli Ritvos ${ }^{\mathrm{b}}$, \\ Heikki Kainulainen ${ }^{\mathrm{a}}$, Ayhan Korkmaz ${ }^{\mathrm{d}}$, Mustafa Atalay ${ }^{\mathrm{d}}$ \\ a University of Jyväskylä, Department of Biology of Physical Activity, Neuromuscular Research Center, P.O. Box 35, FI-40014, Finland \\ ${ }^{\mathrm{b}}$ Department of Physiology, Faculty of Medicine, University of Helsinki, Haartmaninkatu 8, FI-00290 Helsinki, Finland \\ c Syracuse University, Department of Exercise Science, 820 Comstock Ave., 201 WB, Syracuse, NY, USA \\ d Institute of Biomedicine, Physiology, University of Eastern Finland, Yliopistonranta 1 E, 70210 Kuopio, Finland \\ e School of Health Sciences, University of Tampere, Medisiinarinkatu 3, FI-33014, Finland \\ ${ }^{\mathrm{f}}$ Department of Health Sciences, University of Jyväskylä, Rautpohjankatu 8, P.O. Box 35, FI-40014, Finland
}

\section{A R T I C L E I N F O}

\section{Article history:}

Received 6 July 2016

Received in revised form

10 August 2016

Accepted 12 August 2016

Available online 20 August 2016

\section{Keywords:}

Myostatin

$m d x$

ER stress

UPR

\begin{abstract}
A B S T R A C T
Protein homeostasis in cells, proteostasis, is maintained through several integrated processes and pathways and its dysregulation may mediate pathology in many diseases including Duchenne muscular dystrophy (DMD). Oxidative stress, heat shock proteins, endoplasmic reticulum (ER) stress and its response, i.e. unfolded protein response (UPR), play key roles in proteostasis but their involvement in the pathology of DMD are largely unknown. Moreover, exercise and activin receptor IIB blocking are two strategies that may be beneficial to DMD muscle, but studies to examine their effects on these proteostasis pathways are lacking. Therefore, these pathways were examined in the muscle of $m d x$ mice, a model of DMD, under basal conditions and in response to seven weeks of voluntary exercise and/or activin receptor IIB ligand blocking using soluble activin receptor-Fc (sAcvR2B-Fc) administration. In conjunction with reduced muscle strength, $m d x$ muscle displayed greater levels of UPR/ER-pathway indicators including greater protein levels of IRE1 $\alpha$, PERK and Atf6 $b$ mRNA. Downstream to IRE1 $\alpha$ and PERK, spliced Xbp1 mRNA and phosphorylation of eIF2 $\alpha$, were also increased. Most of the cytoplasmic and ER chaperones and mitochondrial UPR markers were unchanged in $m d x$ muscle. Oxidized glutathione was greater in $m d x$ and was associated with increases in lysine acetylated proteome and phosphorylated sirtuin 1. Exercise increased oxidative stress when performed independently or combined with sAcvR2B-Fc administration. Although neither exercise nor sAcvR2B-Fc administration imparted a clear effect on ER stress/UPR pathways or heat shock proteins, sAcvR2B-Fc administration increased protein expression levels of GRP78/BiP, a triggering factor for ER stress/UPR activation and TxNIP, a redox-regulator of ER stress-induced inflammation. In conclusion, the ER stress and UPR are increased in $m d x$ muscle. However, these processes are not distinctly improved by voluntary exercise or blocking activin receptor IIB ligands and thus do not appear to be optimal therapeutic choices for improving proteostasis in DMD.
\end{abstract}

(c) 2016 Elsevier Inc. All rights reserved.

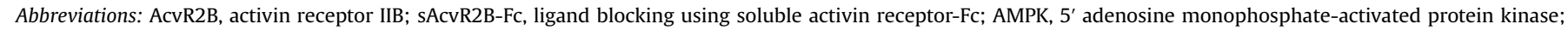

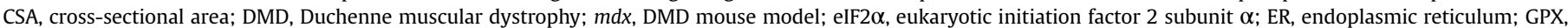

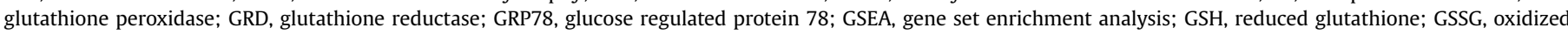

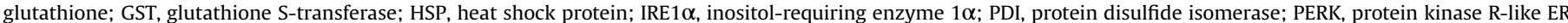

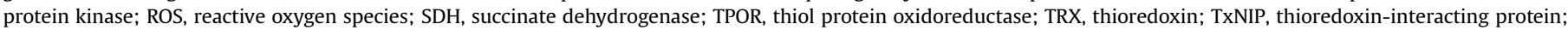
UPR, unfolded protein response; XBP1, X-box binding protein 1

* Corresponding author at: Department of Biology of Physical Activity, University of Jyväskylä, P.O. Box 35, 40014 Jyväskylä, Finland.

E-mail address: juha.hulmi@jyu.fi (J.J. Hulmi).

${ }^{1}$ Present address: Lund University, Department of Experimental Medicine, Lund, Sweden.
} 


\section{Introduction}

Duchenne muscular dystrophy (DMD) is a disease characterized by progressive wasting of skeletal muscle [1]. The absence of functional dystrophin is a major reason for perturbations to cellular changes including abnormal $\mathrm{Ca}^{2+}$ homeostasis, inflammatory cell infiltration, fibrosis, necrosis, regeneration [2] and in turn protein homeostasis (proteostasis) in DMD and its animal model, $m d x$ mice. The restoration of dystrophin expression in all of the muscles and for all of the different mutations is currently unattainable [3]. Therefore, other strategies are being developed that may complement dystrophin restoration approaches.

Oxidative stress is a disruption of thiol redox circuits that results in impaired cell signaling and dysfunctional redox-control $[4,5]$. It is linked to several pathological processes including dysfunction of proteostasis and the accumulation of misfolded proteins in the lumen of the endoplasmic reticulum (ER), resulting in ER stress [6]. Notably, secondary consequences of dystrophin deficiency include the loss of skeletal muscle calcium homeostasis and hypoxia [7,8] as well as deficiency in nitric oxide synthase NOS [2] that can trigger oxidative stress $[9,10]$ and in theory, ER stress. Furthermore, accumulation of improperly folded dystrophin in $m d x$ mice [11] may also cause ER stress. The unfolded protein response in ER (UPR $\mathrm{ER}_{\mathrm{ER}}$ ) resolves ER stress and consists of several branches of signaling pathways aimed to recover proteostasis by increasing the protein folding machinery (chaperones), suppressing the overall translation of proteins and increasing the ER associated protein degradation (ERAD) [12]. Additionally, mitochondrial UPR (UPR $\mathrm{mt}_{\mathrm{mt}}$ ) [13] and cytoplasmic chaperones including heat shock proteins (HSP) [14] prevent accumulation of unfolded or incorrectly folded proteins. When ER stress is too severe or chronic, or the UPR and HSP responses are impaired and unable to cope with the protein-folding defects needed to maintain proteostasis, pro-apoptotic signaling pathways are activated in the cell [12]. Indeed, a recent study showed that glucose regulated protein 78 (GRP78/BiP), which is a triggering factor for ER stress/UPR activation, was associated with ER-related apoptosis signaling in human DMD muscle and/or $m d x$ mice [15]. A more thorough understanding of these processes in muscular dystrophy would provide further insight into the role these factors may play in mediating the disease pathology in order to develop new therapeutic tools.

Type IIb activin receptor (AcvR2B) ligands myostatin and activins inhibit muscle hypertrophy $[16,17]$. Blockade of AcvR2B ligands can be achieved, e.g. by using the soluble ligand binding domain of type IIb activin receptor fused to the Fc domain (sAcvR2B-Fc) to effectively increase muscle size [18-21]. Blocking these proteins using various strategies has been shown to attenuate dystrophic pathology of the $m d x$ mouse in some $[18,22]$, but not in all studies [20,23]. However, the effect of AcvR2B ligand blocking on ER stress and UPR in dystrophic muscle is currently unknown.

Muscular dystrophy is associated with a reduced skeletal muscle oxidative capacity [24]. Exercise improves muscle oxidative capacity in $m d x$ mice $[25,26]$, which as an adaptation could increase resistance to the dystrophic pathology [7]. Exercise training may decrease markers of oxidative stress in $m d x$ mice, but this response may depend on the dose, type, intensity and duration of exercise, and possibly the disease status $[9,10]$. Decreased levels of oxidative stress would be beneficial since ER stress and oxidative stress can work in a positive feed-forward loop in a manner that disrupts cell function and induces pro-apoptotic signaling $[6,27]$. Therefore, the performance of regular, tolerable exercise alone or in combination with other therapeutic tools may positively modulate pathways involved in proteostasis that could alleviate skeletal muscle pathologies.
The overall purpose of this experiment was twofold. One purpose was to investigate for the first time the effects of muscular dystrophy on oxidative stress concurrently with ER stress, UPR and HSP defense. The second purpose was to examine these same physiological states in response to AcvR2B ligand blocking and voluntary exercise training as these interventions may elicit beneficial effects on $m d x$ muscle by altering muscle proteostasis.

\section{Materials and methods}

\subsection{Animals}

Six- to seven-week-old male $m d x$ mice and C57Bl/10ScSnJ controls originating from the same strain (Jackson Laboratories, Bar Harbor, Maine, USA) were used in the experiments. The mice were housed under standard conditions (i.e., $22^{\circ} \mathrm{C}, 12 \mathrm{~h}$ light:dark cycle) and had free access to tap water and food pellets (R36; $4 \%$ fat, $55.7 \%$ carbohydrate, $18.5 \%$ protein, $3 \mathrm{kcal} / \mathrm{g}$, Labfor, Stockholm Sweden).

The treatment of animals was in strict accordance with the European Convention for the Protection of Vertebrate Animals Used for Experimental and Other Scientific Purposes. The protocol was approved by the National Animal Experiment Board (Permit Number: ESLH-2009-08528/Ym-23).

\subsection{Experimental design}

Two experimental designs were used in this investigation: 1) effect of the $m d x$ phenotype on ER stress/UPR and oxidative stress; and 2) exercise and blocking activin receptor ligands on the same parameters in $m d x$ mice. In the first experiment, $m d x$ mice $(\mathrm{n}=8)$ and wild type mice from the same strain (C57Bl/10ScSnJ) $(n=5)$ were compared. In the second experiment, 7-week old $m d x$ mice were randomly divided into four groups in a $2 \times 2$ design $(n=8$ animals/group): 1) sedentary control injected with PBS (vehicle); 2) running wheel and injection with PBS; 3) sedentary injected with SAcvR2B-Fc; and 4) running wheel and injection with sAcvR2B-Fc. sAcvR2B-Fc $(5-\mathrm{mg} / \mathrm{kg})$ or PBS was injected intraperitoneally once per week for seven weeks with or without voluntary wheel running exercise. To allow treatments to take effect, the mice were prevented from exercising by locking the running wheels for two days at the start of the experiment. In order to study only long-term effects of exercise the mice did not have access to running wheels on the last two days of the experiment. During the experiments all the conditions were standardized. At $\sim 14$ weeks of age all the mice were euthanized by cervical dislocation and muscle samples were collected. Forelimb grip strength was measured the day before the sacrifice using the protocols of TREAT-nmd (web-link: http://www.treat-nmd.eu/ downloads/file/sops/dmd/MDX/DMD_M.2.2.001.pdf). The measurements were conducted five times with the highest score (absolute force) taken as the final result.

\section{3. $s A c v R 2 B-F c$ production}

The recombinant fusion protein was produced and purified in house as described previously [19]. The protein is similar, but not identical with that originally generated by Se-Jin Lee [21]. In short, the fusion protein contains the ectodomain (ecd) of human sAcvR2B and a human IgG1 Fc domain. The protein was expressed in Chinese hamster ovary ( $\mathrm{CHO}$ ) cells grown in suspension culture.

\subsection{Voluntary wheel running}

The mice were housed in cages where they had free access to custom-made running wheels (diameter $24 \mathrm{~cm}$, width $8 \mathrm{~cm}$ ) $24 \mathrm{~h} /$ 
day. Sedentary animals were housed in similar cages without the running wheel.

\subsection{Muscle Immunohistochemistry}

Gastrocnemius muscle cross-sections were cut using a cryomicrotome and stained for membrane (caveolin 3 (ab2912, Abcam, UK), dilution 1:100) and captured with Olympus BX-50 fluorescent microscopy. 10x magnification was used and the average fiber number in randomly selected fields of high quality was $342.8 \pm 30.5$ fibers per section. Image analysis of fiber CSA was performed with specific software (ImageJ, U.S. National Institutes of Health, Bethesda, MD, USA).

\subsection{Muscle sampling and homogenization}

The gastrocnemius was immediately removed from the hind limb, weighed, and frozen. The muscle was pulverized and onehalf of the powder was allocated for protein analysis and one-half to RNA isolation. The powder for protein analysis (except enzyme analysis) was homogenized in ice-cold buffer with protease inhibitors (Pierce Biotechnology, Rockford, IL, USA) and total protein measured using the bicinchoninic acid protein assay (Pierce Biotechnology) with an automated KoneLab analyzer (Thermo Scientific, Vantaa, Finland).

\subsection{Western immunoblot analyses}

Western blots were conducted in two laboratories and thus two slightly different protocols are provided below. Unless otherwise stated, all chemicals and reagents were obtained from Sigma-Aldrich (St. Louis, MO, USA) and were of analytic grade or the highest grade available.

\subsubsection{PDI, IRE-1 $\alpha$, PERK, $p$-eIF2 $\alpha /$ eIF2 $\alpha$, Sirtuins, AMPK, lysine acetylation}

Muscle homogenates mixed in Laemmli sample buffer were heated at $95^{\circ} \mathrm{C}$ to denature proteins and processed as described previously $[19,25]$. In short, protein was separated by SDS-PAGE and transferred to a PVDF membrane, blocked and incubated overnight at $4{ }^{\circ} \mathrm{C}$ with primary antibodies. The membrane was then washed and incubated with secondary antibodies (Jackson ImmunoResearch Laboratories, West Grove, PA, USA) for $1 \mathrm{~h}$ followed by washing. Proteins were visualized by ECL (SuperSignal west femto maximum sensitivity substrate, Pierce Biotechnology, Rockford, IL, USA) and quantified using a ChemiDoc XRS device with Quantity One software (version 4.6.3. Bio-Rad Laboratories, Hercules, CA, USA). The uniformity of the protein loading was confirmed by staining the membrane with Ponceau $S$ and by reprobing the membrane with an antibody against GAPDH (Abcam, Cambridge, UK).

\subsubsection{Heat shock proteins, GRP78, TRX and TxNIP}

After SDS-PAGE, proteins were transferred to a nitrocellulose membrane (Millipore, Bedford, Mass., USA) as previously described [28]. The membranes were blocked and after that treated with antibodies overnight at $4{ }^{\circ} \mathrm{C}$. Immunoblots were visualized using an Odyssey Imaging System (Li-Cor Biosciences Inc., Lincoln, NB, USA) and quantified using Odyssey Software.

\subsubsection{Protein carbonyls}

Protein carbonyls were derivatized using 2,4-dinitrophenyl hydrazine immediately before electrophoresis as previously described $[29,30]$. Protein extracts (20 ug protein/lane) were electrophoresed on $12.5 \%$ SDS-PAGE. A rat monoclonal primary antibody raised against 2,4-dinitrophenol (Zymed Laboratories, San
Francisco, CA, USA) was incubated overnight at $4{ }^{\circ} \mathrm{C}$. After secondary antibody incubation, the immunoblots were visualized using an Odyssey Imaging System (Li-Cor Biosciences Inc., Lincoln, NB, USA) and quantified using Odyssey Software.

\subsubsection{Primary antibodies}

The antibodies for inositol-requiring enzyme $1 \alpha$ (IRE1 $\alpha$, \#3294), protein disulfide isomerase (PDI, \#3501), lysine acetylated proteins (\#9441), protein kinase R-like ER protein kinase (PERK, \#3192), eukaryotic initiation factor 2 subunit $\alpha$ (eIF2 $\alpha, \# 5324)$ and its phosphorylated form at ser51 and phosphorylated sirtuin 1 at ser46 in mouse (\#3398) and AMPK total (\#2603) and phosphorylated at Thr172 (\#4188) were purchased from Cell Signaling Technology. Antibodies against GAPDH (ab9485), sirtuin 1 (ab28170), 3 (ab118334) and 6 (ab62739) were from Abcam. Antibodies that recognize the inducible forms of heat shock protein 70 (HSP70, SPA-810), heat shock protein 60 (HSP60, SPA-806), heat shock protein 90 (HSP90, SPA-835), heat shock protein 25 (HSP25, SPA-801), heat shock protein 47 (HSP47, SPA-470) and glucoseregulated protein 78 (GRP78, SPA-826) and 75 (GRP75, SPS-825) were purchased from Enzo Life Sciences Inc., (Farmingdale, NY, USA). Antibody against thioredoxin (ATRX-06) was purchased from IMCO Corp (Stockholm, Sweden), TXNIP (thioredoxin-interacting protein, VDUP-1, \# K0205-3) from MBL (Medical and Biological laboratories Co. Ltd, Nagoya, Japan) and actin (A-2066) and HSP10 (SAB4501465) from Sigma-Aldrich (St. Louis, MO, USA).

\subsection{Assays for glutathione levels and antioxidant enzyme activity}

\subsubsection{GSSG/TGSH}

Gastrocnemius muscle was homogenized on ice in brief bursts by an Ultra-Turax homogenizer (Janke and Kunkel, Germany) in a $1: 10(w: v)$ dilution of ice-cold 5.0\% metaphosphorous acid. Resultant homogenates were centrifuged at $10,000 \mathrm{~g}$ for $15 \mathrm{~min}$ $\left(4{ }^{\circ} \mathrm{C}\right)$, and the supernatant was stored at $-70^{\circ} \mathrm{C}$. On the day of measurement the supernatant was diluted with distilled water and TGSH was measured spectrophotometrically by a GSSG reductase recycling method as described earlier [31]. The rate of change in absorbance at $412 \mathrm{~nm}$ was monitored with double-beam spectrophotometer at room temperature and tissue concentrations were estimated by linear regressions from the standard curve.

\subsubsection{GPX, GRD, GST and TPOR}

Total glutathione peroxidase (GPX) activity was determined with cumune hydroperoxide as substrate. Glutathione reductase (GRD) activity was determined in the presence of $50 \mathrm{mM}$ Tris- $\mathrm{HCl}$ buffer with $1 \mathrm{mM}$ EDTA, $2 \mathrm{mM}$ NADPH, and $20 \mathrm{mM}$ GSSG by monitoring the decrease in absorbance per minute due to the oxidation of NADPH at $340 \mathrm{~nm}$. GST activity was also assayed at $340 \mathrm{~nm}$ with 1,2-dichloro-4-nitrobenzene as substrate. Activities of muscle GPX, GRD, and GST were determined from the cytosolic supernatant spectrophotometrically, as described previously [32]. Thiol-Protein Oxidoreductase Activity (TPOR) to demonstrate PDI activity was assayed as earlier [33], in which the enzyme-catalyzed reduction of the disulfide bonds of insulin by GSH is linked to the reduction of GSSG to GSH, by NADPH and glutathione reductase; the linked reaction is monitored by spectrophotometer at $340 \mathrm{~nm}$.

\subsection{RNA and DNA isolation and CDNA synthesis}

Gastrocnemius muscle was pulverized and homogenized in liquid nitrogen after which 65-75 mg of muscle powder was placed into Trizol reagent (Invitrogen, Carlsbad, CA, USA). Total RNA was extracted according to the manufacturer's guidelines and analyzed in duplicate using a Nanodrop ND-1000 (Thermo Fisher Scientific Inc., Waltham MA, USA). Any possible remaining DNA was further 
degraded using DNAse kit (TURBO DNA-free ${ }^{\mathrm{TM}}$ Kit, Applied Biosystems by Life Technologies, South San Francisco, CA, USA) prior to mRNA analysis. The quality of RNA was confirmed spectrophotometrically $\left(\mathrm{OD}_{260} / \mathrm{OD}_{280}\right.$ ratio of $\left.1.9-2.0\right)$, by agarose gel electrophoresis as well as the Agilent Bioanalyzer (Agilent Technologies Inc., Santa Clara, CA, USA).

\subsection{Microarray analysis}

RNA samples from $m d x$ mice ( $\mathrm{n}=5$ mice/group) and the control $(n=4)$ were analyzed with a Illumina Sentrix MouseRef-8 v2 Expression BeadChip containing approximately 25,600 annotated transcripts and over 17,900 unique genes (Illumina Inc., San Diego, CA, USA) by the Finnish Microarray and Sequencing Centre at the Turku Centre for Biotechnology according to the manufacturer's instructions. Raw data were normalized with quantile normalization (including log2-transformation of the data) and data quality was assessed using Chipster software (IT Centre for Science, Espoo, Finland) [34] and R with Limma package software [35]. The normalized gene expression data were imported into Excel spreadsheets (Microsoft Corp., Redmond, WA, USA). From the genes represented by multiple probes, the probe with the highest fold-change ratio was used for further analysis. MIAME guidelines were followed during array data generation, preprocessing, and analysis.

\subsection{Real-time $q R T-P C R$}

Three $\mu \mathrm{g}$ of total RNA were reverse transcribed to synthesize cDNA using a High Capacity cDNA Archive Kit (Applied Biosystems, Foster City, Ca, USA). The mRNA expression levels were quantified with Real-time qPCR according to standard procedures using iQ SYBR Supermix (Bio-Rad Laboratories) and CFX96 Real-Time PCR Detection System (Bio-Rad Laboratories). Real-time qRT-PCR was conducted under standard PCR conditions as recommended by the manufacturer (Applied Biosystems, Foster City, CA, USA) in triplicate. The spliced variant of X-box binding protein 1 (sXbp1) was analyzed using SYBR green primers: forward: TGCTGAGTCCGCAGCAGGTG and reverse: CTGATGAGGTCCCCACTGACAGA with product length of $251 \mathrm{bp}$ (496 - 746) (Invitrogen, USA). qPCR for C/ EBP homologous protein (Chop/Ddit3, assay ID qMmuCID0020314), activating transcription factor 6b (ATF6b, qMmuCID0022729) and caseinolytic peptidase (ClpP, qMmuCID0005629) were conducted using pre-designed Bio-Rad PrimePCR ${ }^{\text {TM }}$ SYBR $^{\circledR}$ Green Assays. The gene expressions were normalized to the expression of stably acted Gapdh (Taqman probe: Mm99999915_g1). The analysis was conducted using the delta delta $\mathrm{Ct}(\Delta \Delta \mathrm{Ct})$ method and quantification was performed in the exponential amplification phase.

\subsection{Data analysis}

All data, with the exception of microarray, were evaluated by analysis of variance (ANOVA) followed by Tukey's post-hoc test (treatments) or t-test ( $m d x$ vs. control). The level of significance in these analyses was set at $\mathrm{P}<0.05$. Data are expressed as mean$\mathrm{s} \pm \mathrm{SE}$. Correlations were analyzed using Pearson's Product Moment Coefficient.

The list of differentially expressed genes generated between the $m d x$ and wild type sample groups from the microarray data were detected utilizing linear modeling and empirical Bayes methods of the Limma package of $\mathrm{R}$. The resulting raw $\mathrm{p}$-values were adjusted using the Benjamini and Hochberg method. The genes with an adjusted $P \leq 0.05$ and absolute fold change higher than 1.5 were considered to be differentially expressed. Enrichment of functionally related genes in three different gene set collections was first performed using a non-biased method by Gene Set Enrichment Analysis software (GSEA; Version 2.0). For this analysis, ranking lists representing different ratio combinations of the normalized data were created by averaging the group results for each gene. The enriched gene sets were ranked based on their fold-change ratios. The collection used was the Canonical Pathways collection (1452 gene sets, C2: CP, version 3.0) (http:// www.broadinstitute.org/gsea/msigdb/collections.jsp). The number of permutations by gene set was set to 1000 and gene sets with at least five, and no more than 500 genes were taken into account in each analysis. Each analysis was carried out at least five times and all the results were averaged into a single value. The statistical significance was calculated using false discovery rate (FDR). The level of significance was set at FDR $<0.05$.

Further, the differentially expressed genes were uploaded to DAVID functional annotation tool [36] to analyze the effects of the phenotype. The enrichment analysis was run against the default gene groups including gene ontologies and KEGG-pathways. The Disulfide bond was highly enriched within the DAVID results, and thus the genes within this pathway with most striking regulation, i.e. having an absolute fold change $\geq 3$ and $P<0.05$, were more carefully studied with hierarchical clustering. The expression values of these genes were analyzed with hierarchical clustering and illustrated with a heatmap using MATLAB. Within clustering, the Euclidean distance and Ward's minimum variance criterion linkage method was used.

\section{Results}

\subsection{Reported skeletal muscle characteristics}

This study is a follow-up to work that was previously published $[25,26]$. In brief, muscles of $m d x$ mice typically contained centrally nucleated fibers and a large content of fibrosis and proliferative cells other than muscle fibers. sAcvR2B-Fc administration increased the mass of all muscles weighed. Wheel running exercise performed by the $m d x$ mice enhanced markers of muscle aerobic capacity (e.g. citrate synthase and SDH activities as well as gene sets of aerobic metabolism in microarray) to levels similar to, or higher than those observed in healthy mice.

\subsection{Effects of mdx phenotype on muscle morphology and grip strength}

No difference in mean fiber cross-sectional area (CSA) was observed in $m d x$ mice when compared to wildtype mice $(P=0.70$, Fig. 1A), but fiber size distribution tended to show differences (Fig. 1B). Statistically, this could be observed as a greater percentage of very small $\left(<600 \mu \mathrm{m}^{2}\right)$ or small $\left(<1000 \mu \mathrm{m}^{2}\right)$ fibers in $m d x$ mice $(P<0.05)$, which represents newly regenerating fibers (Fig. 1C). Along with the higher percentage of very small fibers, lower grip strength presented as absolute values (Fig. 1D) or normalized to body weight (not shown) was also observed among $m d x$ mice $(P<0.05)$.

\subsection{Effects of $m d x$ phenotype on redox balance}

Recent studies showed increased oxidative stress as one candidate mechanism that may mediate the pathology of dystrophin deficiency $[9,10]$. Dystrophic $m d x$ mice at the age of $\sim 14$ weeks showed significantly greater levels of oxidized glutathione (GSSG) $(P<0.05)$ compared to healthy wild type animals (Fig. 2A-C). No effect of muscular dystrophy was seen on protein content of redox-active proteins, TxNIP and TRX (Fig. 2D).

Next, a gene clustering analysis was conducted from microarray 


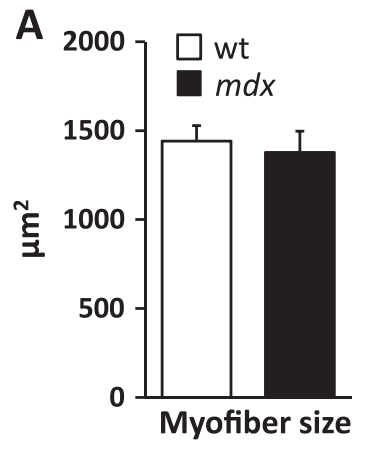

C

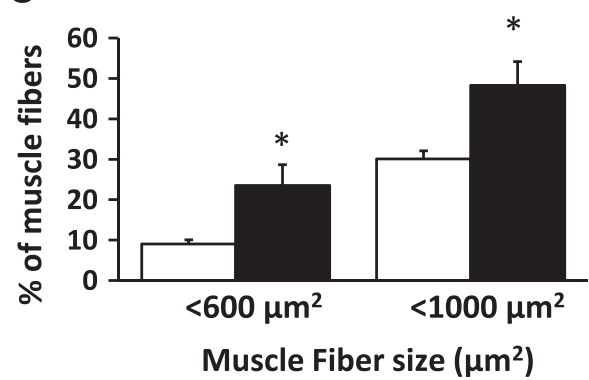

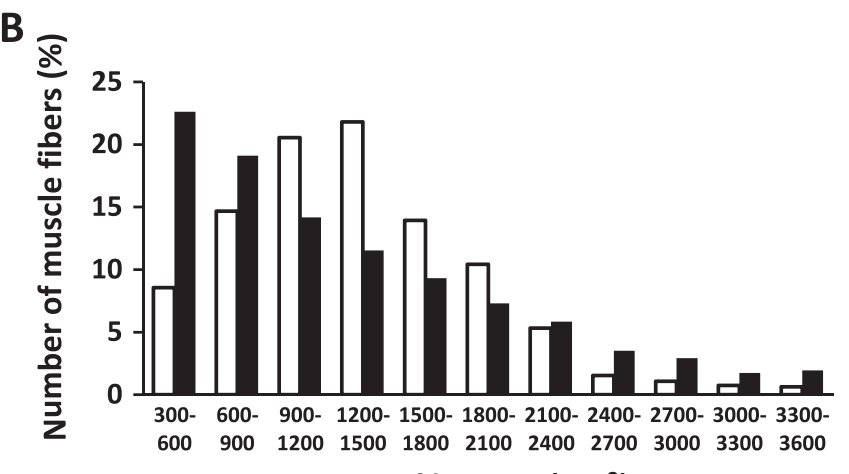

Myofiber size $\left(\mu \mathrm{m}^{2}\right)$

D

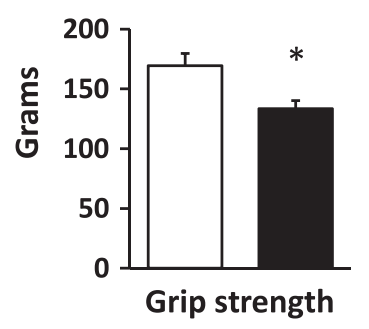

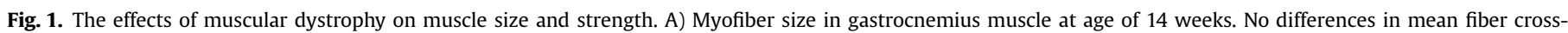

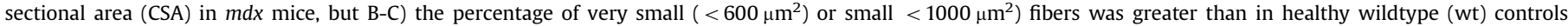
$(P<0.05)$. D) Healthy wild type mice had greater grip strength $(P<0.05)$ than $m d x$ mice. Data are mean $\pm \mathrm{s} . \mathrm{e} . \mathrm{m}$; $\mathrm{n}=8$ for $m d x$ and $\mathrm{n}=5$ for wt.
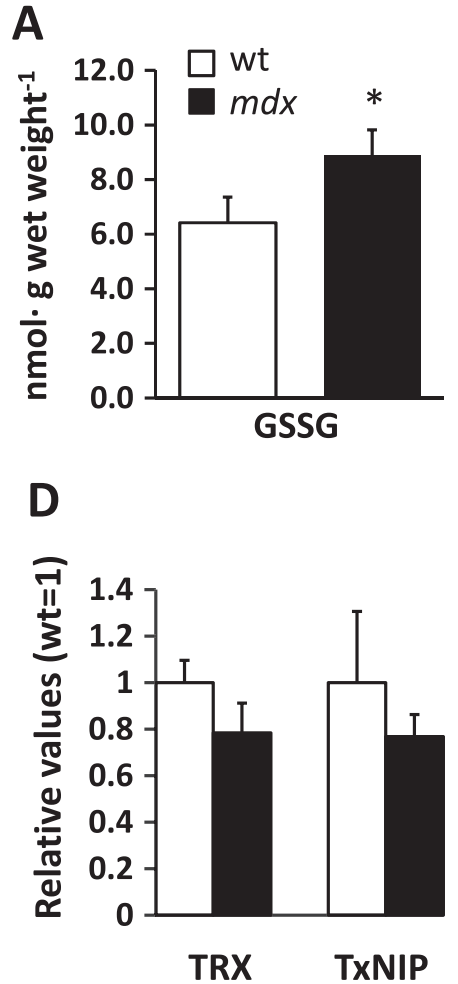
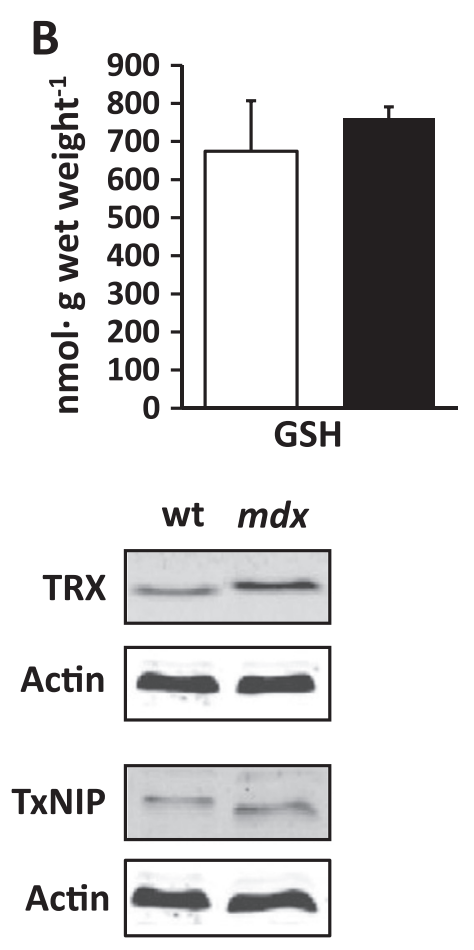

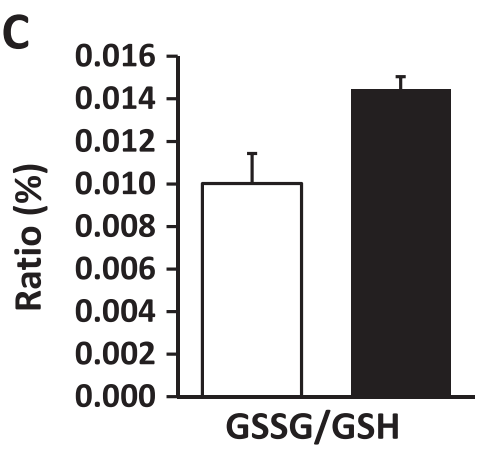

E

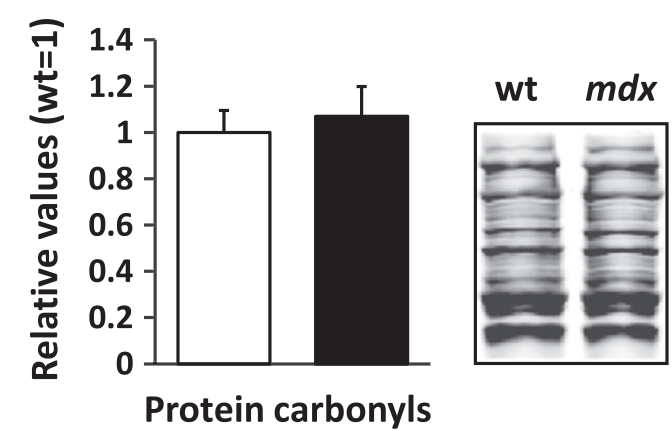

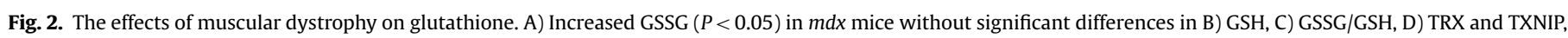
or E) protein carbonyls. Data are mean \pm s.e.m; $n=8$ for $m d x$ and $n=5$ for wt except $n=4$ for glutathione results.

data with a gene set enrichment analysis (GSEA) that is designed to find physiologically meaningful results from large gene sets with $<20 \%$ average changes in individual gene expression [37]. A trend for decreased pathways of glutathione $(F D R=0.07)$ metabolism was observed in $m d x$ mice compared to healthy mice (Fig.
S1 and Table S1), which further supports the presence of altered redox balance in $m d x$ mice.

In addition, anti-oxidative enzyme activities related to redox balance and glutathione metabolism (glutathione reductase (GRD), glutathione S-transferase (GST), glutathione peroxidase (GPX) and 


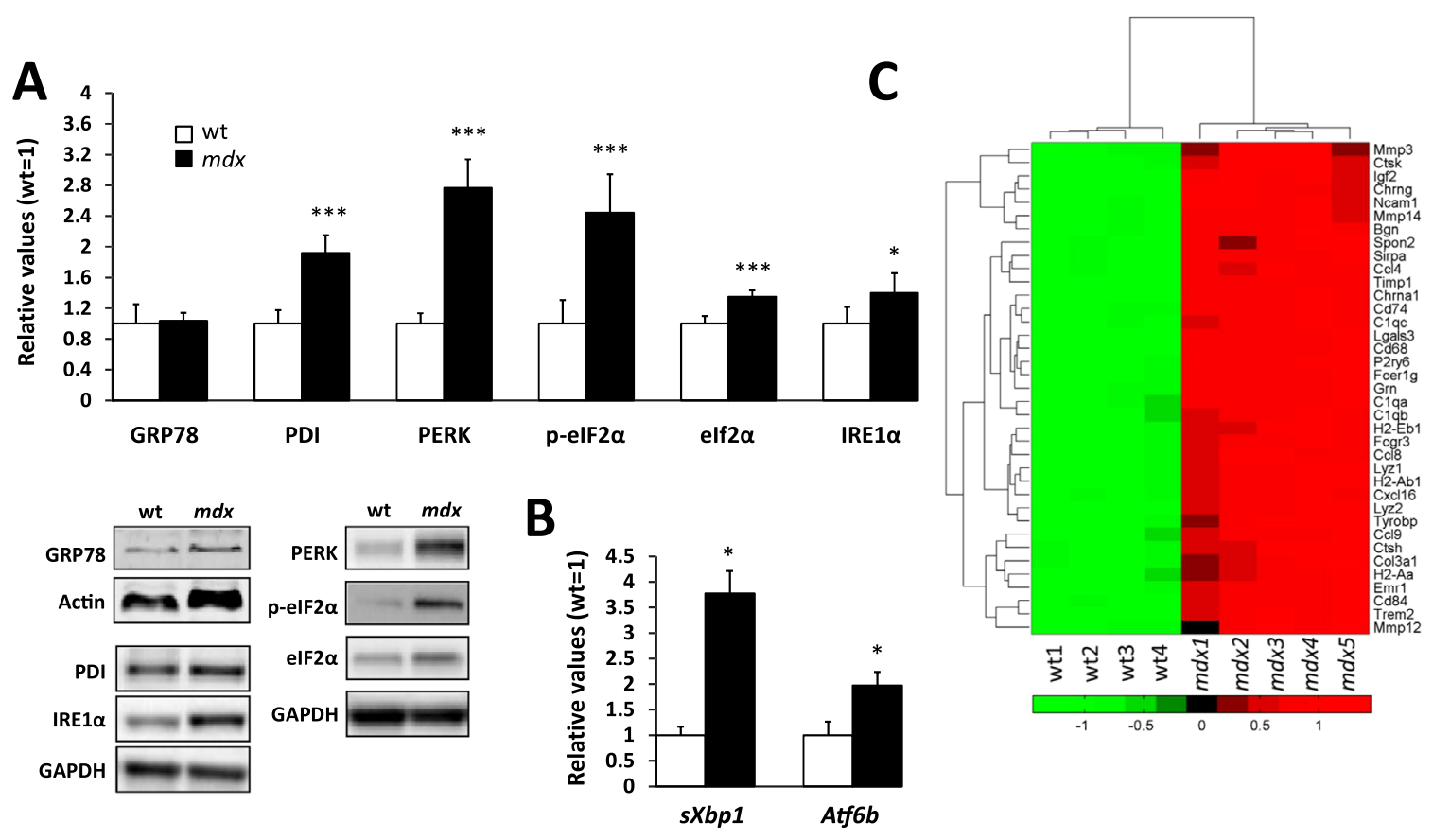

D

$\mathbf{E}$
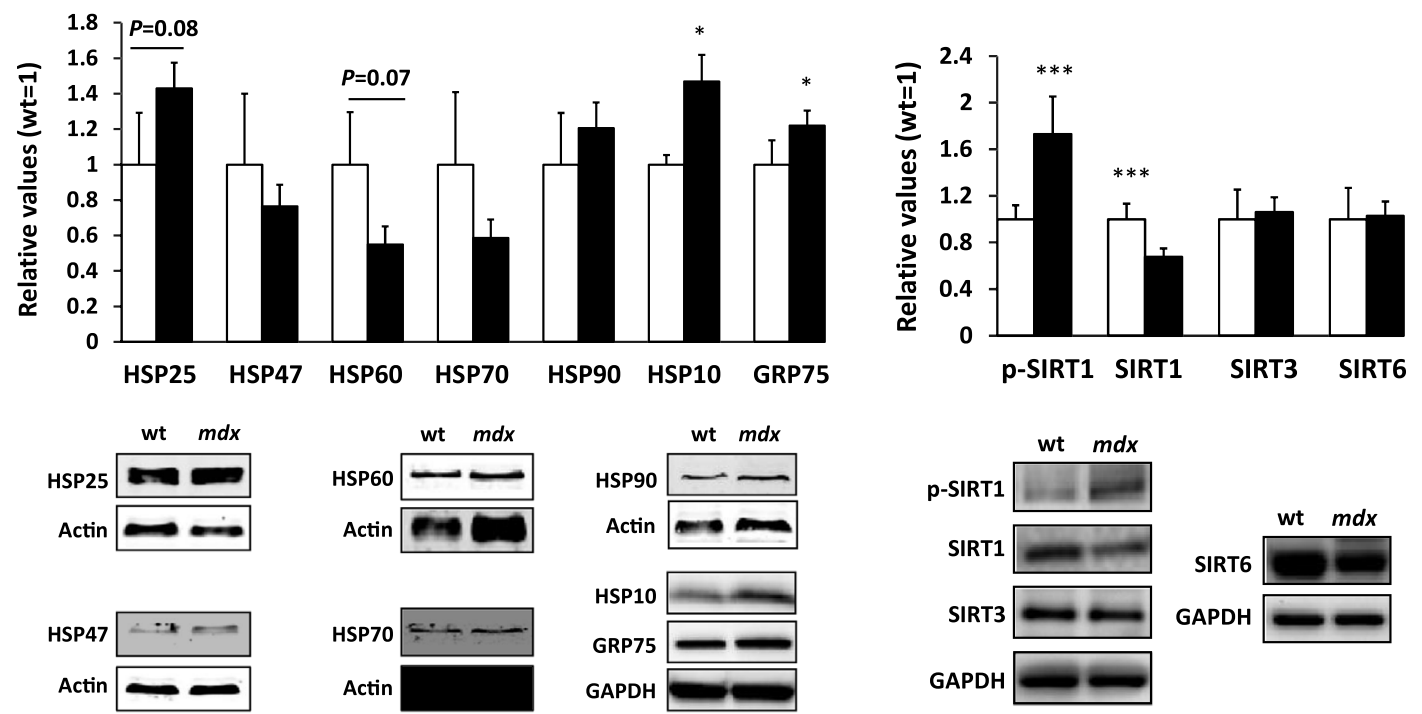

$\mathbf{F}$
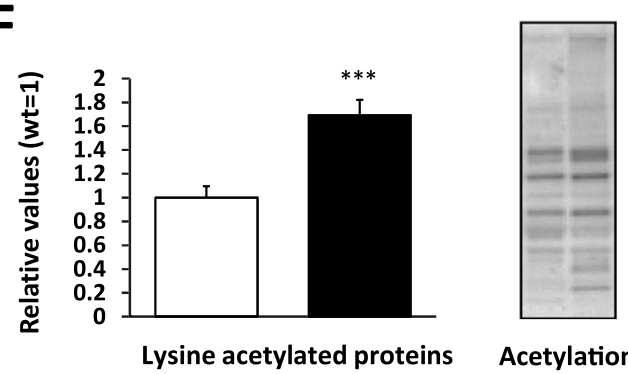

wt $m d x$

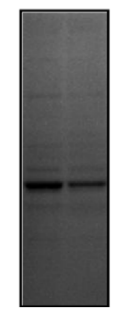

Acetylation Ponceau S

Fig. 3. The effects of muscular dystrophy on ER stress, UPR activation, sirtuins and acetylated proteins. A) Most UPR/ER stress markers (PDI, PERK, p-eIF2 $\alpha$, eIF2 $\alpha$, and IRE1 $\alpha$ proteins were upregulated $(P<0.05-0.001)$ in muscle from $m d x$ mice. B) Spliced Xbp1 (sXbp1) and Atf6 mRNA. C) Hierarchical clustering of the gene-wise standardized logarithmic expression values of the genes within disulfide bond pathway that were up-regulated (FC $\geq 3$ and $P<0.05$ ) in dystrophic $m d x$ muscle vs. wildtype muscle. D) No major differences were noticed in most of the HSPs between $m d x$ and wt mice except mitochondrial proteins HSP10 and GRP75 which were increased in $m d x$ mice $(P<0.05)$. E) Higher p-SIRT1, but lower total SIRT1 in $m d x$ mice $(P<0.001)$, but no changes in other sirtuins $(P>0.05)$. F) Increased acetylated lysine residues in $m d x$ mice $(P<0.001)$. Data are mean \pm s.e.m; $\mathrm{n}=8$ for $m d x$ and $\mathrm{n}=5$ for wt. 
thiol protein oxidoreductase (TPOR)) were measured in order to assess antioxidant capacity, the oxidative protein folding and protein disulfide isomerase (PDI) activity in mdx mice (Fig. S2). There were, however, no significant differences in any of the four measured enzyme activities. Similarly, no effect of the $m d x$ phenotype on protein carbonyls, a marker of oxidative damage to proteins, was observed (Fig. 2E).

3.4. Greater ER stress and $U P R_{E R}$ is observed in $m d x$ muscle, without systematic changes in HSP proteins or $U P R_{m t}$

In order to achieve a more comprehensive view of the muscle cellular stress state of $m d x$ mice, ER stress and UPR $\mathrm{ER}_{\text {were ana- }}$ lyzed. Regardless of no significant effect of muscular dystrophy on GRP78/BiP (Fig. 3A), all three canonical branches of the UPR $\mathrm{ER}_{\mathrm{ER}}$ and their downstream responses were upregulated in $m d x$ mice. More specifically, higher protein content of PDI $(P<0.001)$ and PERK $(P<0.001)$ were detected in $m d x$ muscle. In addition, downstream to PERK, phosphorylated eIF2 $\alpha$ at serine $51(P<0.001)$, and total eIF2 $\alpha$ protein $(P<0.001)$ as well as p-eIF2 $\alpha$ per total eIF2 $\alpha$ $(P<0.05)$ were significantly increased in $m d x$ mice (Fig. 3A). Another UPR pathway component IRE $1 \alpha(P<0.05$; Fig. $3 A)$ and downstream to it spliced Xbp1 $(s X b p 1)$ mRNA $(P<0.05)$ were also increased in $m d x$ mice (Fig. 3B). In addition, mRNA levels of the third UPR sensor Atf6b were also upregulated in $m d x$ muscles in microarray $(1.4$-fold, adjusted $P<0.001)$ and this was confirmed by qPCR (Fig. 3B). In addition, the third-most upregulated gene set in the microarray DAVID analysis was disulfide bond (fold enrichment $2.13, \mathrm{FDR}=4 \times 10^{-24}$, Fig. $3 \mathrm{C}$ ); a set of genes related to protein folding and thus to ER stress, since ER is one of the major sites for disulfide bond formation. To further understand the role of UPR proteostasis in ER, apoptotic pathway components downstream to PERK, Atf4-Chop-Gadd34 were quantified with microarray and qPCR. In microarray Atf4 (1.3-fold), Chop (1.3-fold and qPCR NS. Fig. S3) and Gadd34 (1.4-fold) were unaltered or marginally decreased $(P<0.05)$. This suggests that UPR through PERKeIF2 $\alpha$ cascade and translational halt can override PERK-ATF4CHOP-GADD34 apoptosis pathway at least at age of week 14 in mdx mice.

In addition, several HSPs were measured because of their key role as chaperones that assist with the proper folding of polypeptides into functional proteins and prevent the aggregation of misfolded proteins mainly in the cytosol compartment, but also in other cellular organelles including mitochondria. However, unlike responses of the $U P R_{E R}$ our results did not display significantly altered levels of HSP-proteins (Fig. 3D). Next, UPR in mitochondria, i.e., $\mathrm{UPR}_{\mathrm{mt}}$ and mitochondrial chaperones were examined. In microarray only marginal (1.1-1.3 fold) changes were observed in the $\mathrm{UPR}_{\mathrm{mt}}$ markers Hsp60, Clpp, Jnk2, Timm17a, Hsp10, Yme1l1, Cebpb, Jun, Hsp74 and Pmpcb (data available at GEO: http://www.ncbi. nlm.nih.gov/geo/; accession no. GSE52766) of which Clpp (Fig. S3) and HSP60 (Fig. 3D) were confirmed with qPCR or western blotting, respectively. However, the protein levels of $U_{P R}$ marker HSP10 and mitochondrial chaperone GRP75 were slightly increased in $m d x$ mice (Fig. 3D).

\section{5. $m d x$ muscle shows alteration of p-SIRT1/SIRT1 and increased total lysine acetylated proteins}

Phosphorylated SIRT1 and AMPK (p-SIRT1 and p-AMPK), and protein levels of SIRT1, SIRT3, SIRT6 and AMPK were measured due to their redox, heat shock response and $U_{P R}$ properties and possible effects on muscle dystrophy [7,38]. Increased p-SIRT1 and decreased total SIRT1 were observed in $m d x$ (Fig. 3E) mice leading to increased ratio of phosphorylated SIRT1 to total SIRT1 $(P<0.001)$. No effect on total sirtuins 3 or 6 (Fig. 3E) or phosphorylated AMPK (Fig. S4) was observed. In addition, overall proteome lysine residue acetylation analysis revealed that $m d x$ mice had higher levels of acetylated protein lysine residues $(P<0.001$; Fig. 3F).

\subsection{Effects of exercise and blocking AcvR2B ligands on muscle morphology and grip strength}

Blockade of AcvR2B ligands using sAcvR2B-Fc or placebo (PBS) was administered for seven weeks with or without voluntary running exercise in young male $m d x$ mice. Increased muscle mass by sAcvR2B-Fc, as reported earlier [25,26], did not translate into greater gastrocnemius muscle fiber size or grip strength either presented as absolute values (Fig. S5) or normalized to body weight (not shown). In addition, no effect of exercise was noticed on grip strength, but exercise shifted the CSA distribution further towards smaller fibers (Fig. S5), along with smaller gastrocnemius mass after running as previously published [25]. No statistically significant difference was noted in the percentage mean count of small fibers $\left(<600 \mu \mathrm{m}^{2}\right)$ by running vs. no running $(2 \times 2$ ANOVA $P>0.29)$ and thus the decreasing effect of exercise was throughout the fiber size range.

\subsection{Redox balance and oxidative stress are affected by running and blocking AcvR2B ligands}

Oxidized glutathione (GSSG and GSSG/GSH ratio) in gastrocnemius muscle was increased by running $(2 \times 2$ ANOVA running effect $P<0.05$; Fig. $4 \mathrm{~A}-\mathrm{C}$ ). No difference in reduced glutathione (GSH) was observed between the treatments. In addition, microarray data showed that combination of sAcvR2B-Fc and exercise significantly increased gene sets of glutathione metabolism $(F D R<0.01)$ with a smaller increasing effect of running or sAcvR2B-Fc alone (Fig. S1 and Table S1).

Thiol-Protein Oxidoreductase Activity (TPOR), which reflects the major PDI function, showed a sAcvR2B-Fc and running interaction effect in gastrocnemius muscle $(P<0.05)$ (Fig. 4D). There was no consistent effect of the interventions on the enzyme activities of GRD, GST or GPX (Fig. S6).

Exercise increased protein carbonyl levels $(2 \times 2$ ANOVA running effect $P<0.05$; Fig. 4E). Furthermore, the exercise response also interacted with administration of sAcvR2B-Fc $(2 \times 2$ ANOVA sAcvR2Fc and running interaction effect, $P<0.05$; Fig. $4 \mathrm{E}$ ). The interaction effect was further seen in a post hoc test as running increased protein carbonyls only in the group administered with sAcvR2-Fc (sAcvR2-Fc + running vs. sAcvR2-Fc alone, $P<0.05$; Fig. 4E).

\section{8. $s A c v R 2 B-F c$ increased GRP78/BiP and TxNIP, but neither treat- ment altered UPR markers or HSPS}

sAcvR2B-Fc increased a marker of ER stress/UPR, GRP78/BiP $(2 \times 2$ ANOVA sAcvR2B-Fc administration effect, $P<0.05)$ (Fig. 5 A). TxNIP, an endogenous inhibitor of antioxidant TRX and a protein induced in ER stress [39] was also increased due to sAcvR2B-Fc $(2 \times 2$ ANOVA drug effect, $P<0.05$; Fig. $5 B)$. Supporting the link between ER stress and TxNIP protein, these two proteins also strongly correlated with each other in $m d x$ mice $(r=0.876$, $P<0.001$ ) (Fig. S9). No effect of the treatments was found on TRX protein (Fig. 5C).

No systematic effect of SAcvR2B-Fc was seen in ER stress or $\mathrm{UPR}_{\mathrm{ER}}$ (PDI, IRE1 $\alpha$, PERK, p-eIF2 $\alpha$ at $\operatorname{ser}^{51}$ and eIF2 $\alpha$ and total eIF $2 \alpha$ ) protein levels or Xbp1 mRNA splicing levels (Fig. 6A-E). However, exercise tended to increase PDI and IRE $1 \alpha(2 \times 2$ ANOVA running-effect, $P=0.07-P=0.08$; Fig. $6 \mathrm{~A}-\mathrm{B})$. According to microarray data, there was no effect of interventions on mRNA expression in ER stress or $\mathrm{UPR}_{\mathrm{ER}}$ related genes (Grp78, Perk, eif2 $\alpha$ and 
A

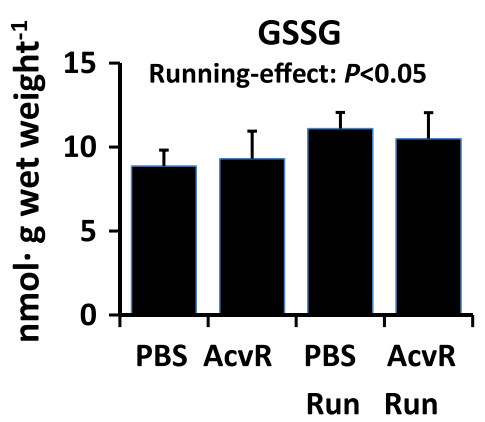

D

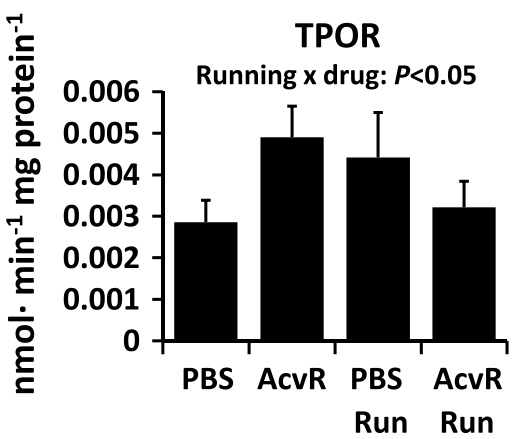

B

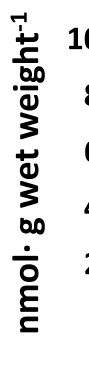

1000
800
600
400
200
0

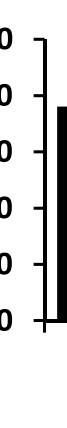

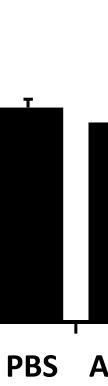

GSH

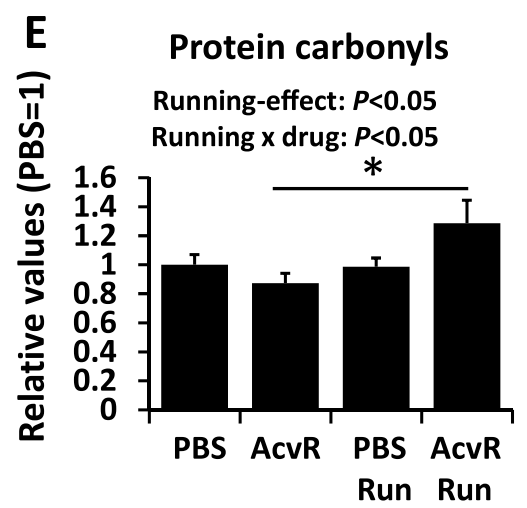

C

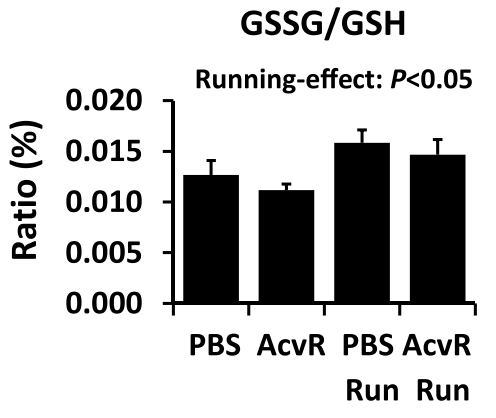

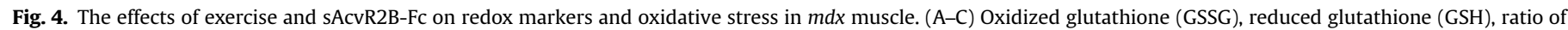

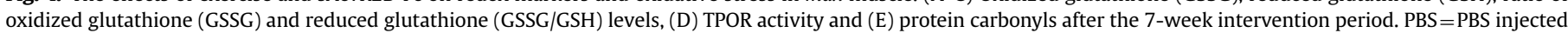

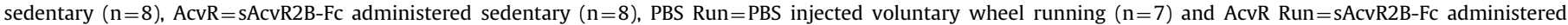

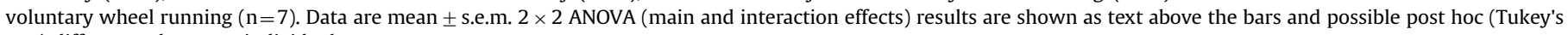
test) differences between individual groups.

Ire1 $\alpha$, Atf4, Chop, Gadd34, Pdi, Xbp1, and Atf6; $P>0.85$, data not shown). There were also no systematic effects of exercise or sAcvR2B-Fc administration alone or in combination on HSPs
(Fig. 7). However, exercise tended to increase HSP70 ( $\mathrm{P}=0.07)$ (Fig. 7B) and decreased HSP90 protein $(2 \times 2$ ANOVA running effect, $P<0.05$, Fig. $7 C$ ). There were also no effects of treatments on
A

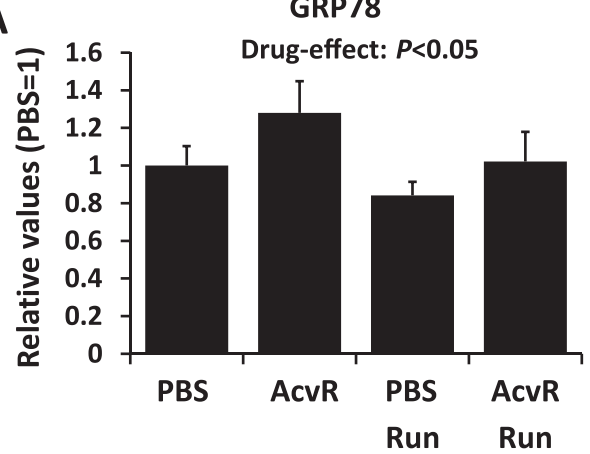

C

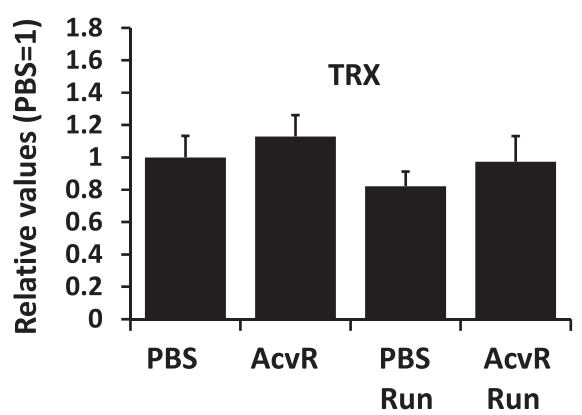

B
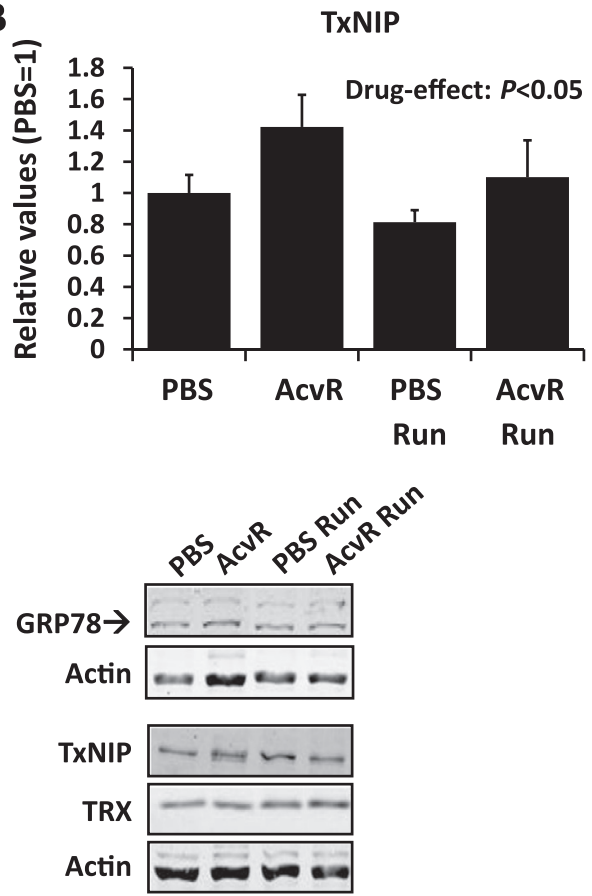

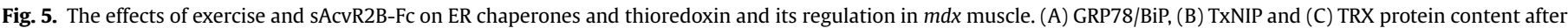

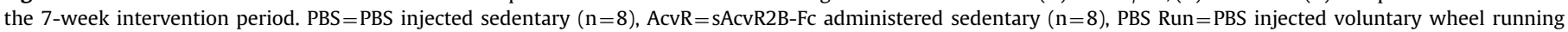

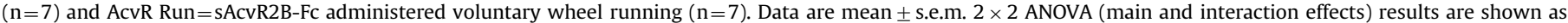
text above the bars. There were no post hoc (Tukey's test) differences between individual groups. 
A

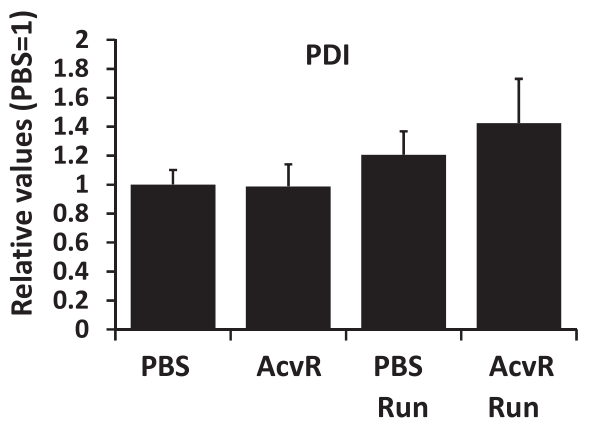

C

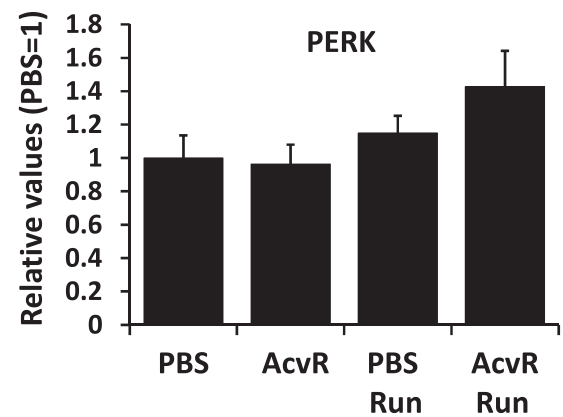

D

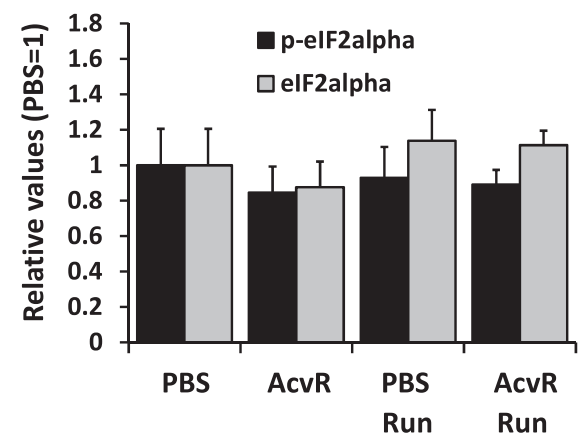

B

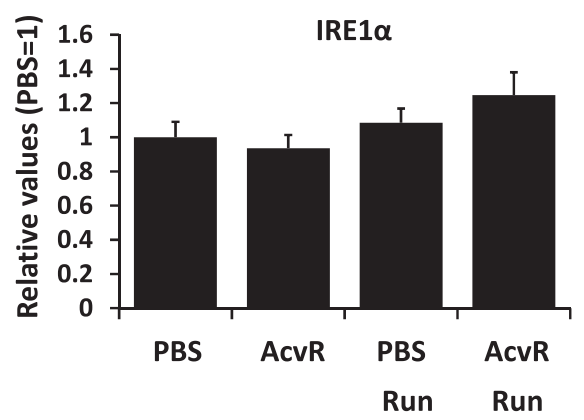

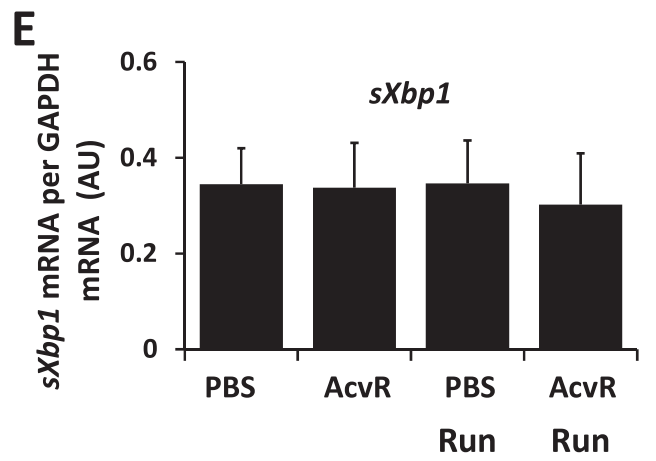

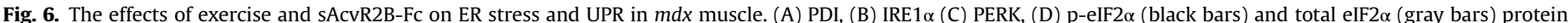

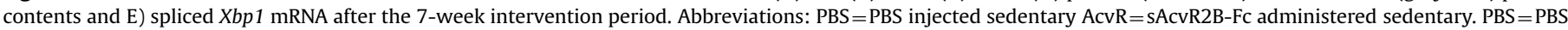

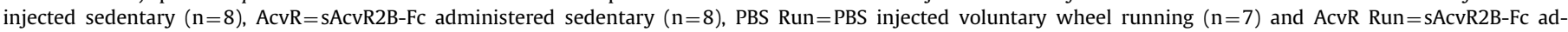
ministered voluntary wheel running $(n=7)$. Data are mean \pm s.e.m.

$\mathrm{UPR}_{\mathrm{mt}}$. markers such as HSP60 protein and in microarray Clpp, JNK2, Timm17a, HSP10, Yme1l1, Cebpb, Jun, HSP74 and Pmpcb mRNA $(P>0.85$, data not shown).

\subsection{AMPK, Sirtuin 1 and lysine acetylated proteins are affected by the treatments}

No effect of exercise or sAcvR2B-Fc on pAMPK $\alpha$ at $\operatorname{Thr}^{172}$, total
AMPK or p-AMPK/AMPK was observed, but p-AMPK/AMPK showed a running $\mathrm{x}$ drug interaction effect $(2 \times 2$ ANOVA, $P<0.05$; Fig. S7). The phosphorylated sirtuin 1 (p-SIRT1 at Ser ${ }^{46}$ ) showed both sAcvR2B-Fc administration $(2 \times 2$ ANOVA, $P<0.05)$ and running $x$ sAcvR2B-Fc administration interaction effects $(2 \times 2$ ANOVA, $P<0.05$ ) (Fig. S7). This was due to a fact that sAcvR2B-Fc increased p-SIRT1 in the exercised mice $(P<0.05)$ and not in sedentary mice (Fig. S7). The ratio of p-SIRT1 to total SIRT1 (p-SIRT1/ 
A

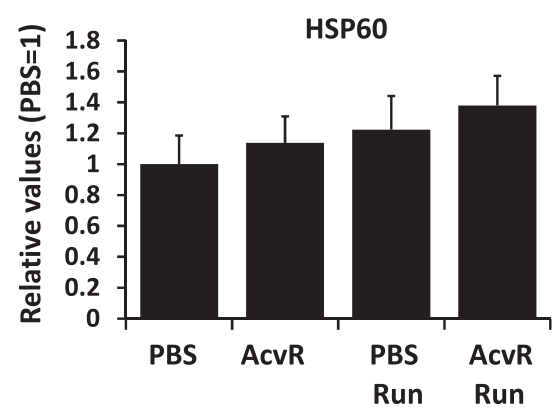

C

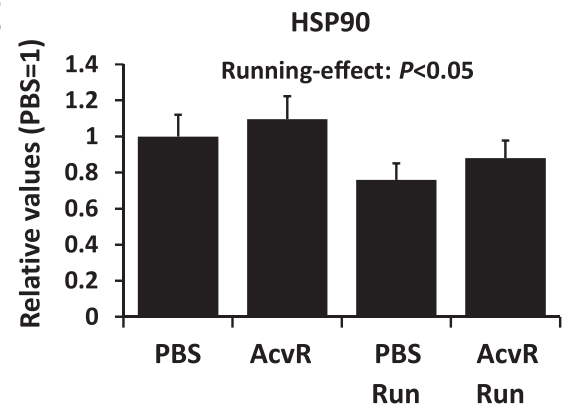

B

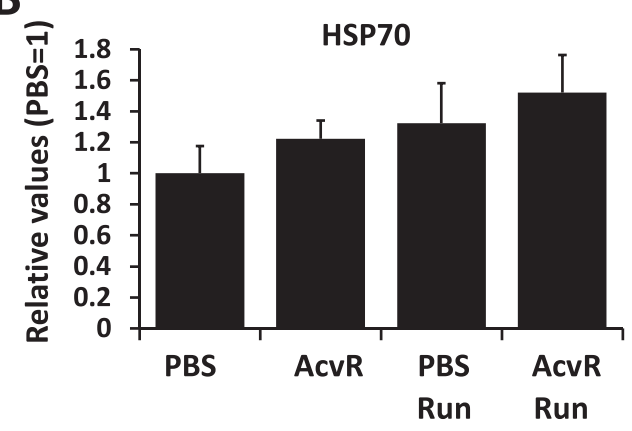

D

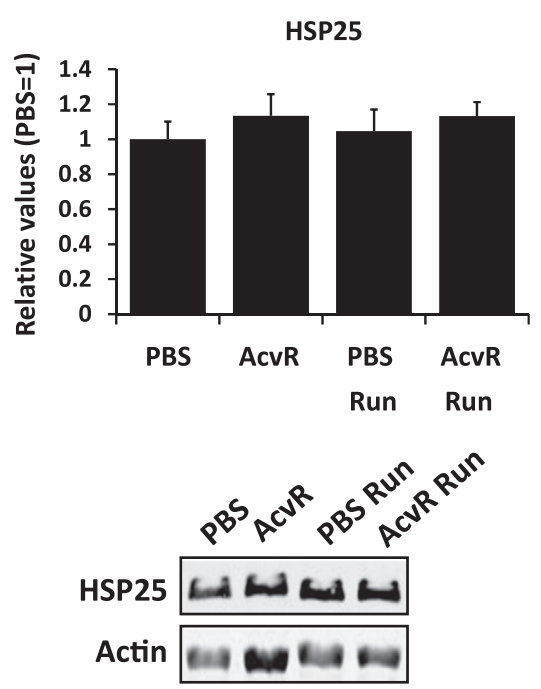

E

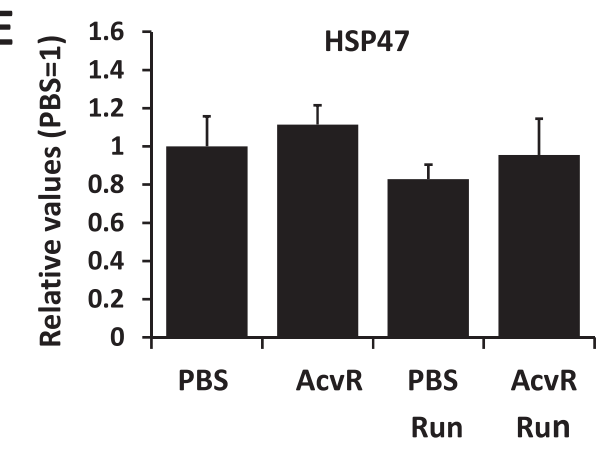

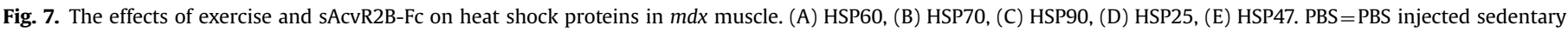

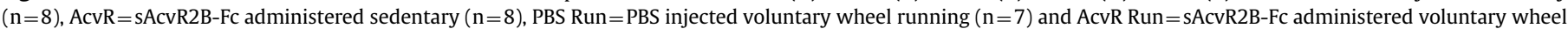

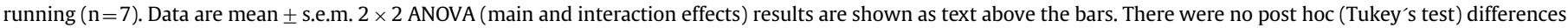
between individual groups.

SIRT1) was in line with the p-SIRT1 result (not shown). There were no significant differences in the protein expression levels of SIRT3 or SIRT6 between the treatments (Fig. S7). Running increased levels of protein acetyls at lysine residues $(2 \times 2$ ANOVA, $P<0.05$; Fig. S8).

\subsection{Associations between the measured variables}

A computationally determined network was created between different variables. For this purpose, biologically similar variables were merged. Katiska/Himmeli software using in GNU Octave program environment (http://www.finndiane.fi/software/katiska/) was used for analysis [40]. Clearly, different HSPs were connected and a link to UPR/ER stress was also evident (Fig. 8A). UPR/ER stress was also linked to acetylated proteins and protein carbonyls to mitochondria count (Fig. 8A). Of individual associations, TxNIP correlated strongly and positively with HSPs in $m d x$ mice $(P<0.01-P<0.001)$ (Fig. S9). Especially interesting was the strong correlation between TxNIP and GRP78 as mentioned earlier (Fig. S9). Carbonyls correlated positively and strongly in the sAcvR2B-Fc injected mice with activity index $(r=0.87, P<0.001)$ that was assessed by measuring the whole activity level of mice in the cage (running and non-running) (Fig. S9), a measure reported earlier [26]. Fig. 8B summarizes the main effects of muscular dystrophy on ER stress/UPR/chaperones in the present manuscript.

\section{Discussion}

The present study provides an extensive analysis of the effects of muscular dystrophy on various types of metabolic stress and two candidate therapeutic strategies to treat dystrophin deficient 
A

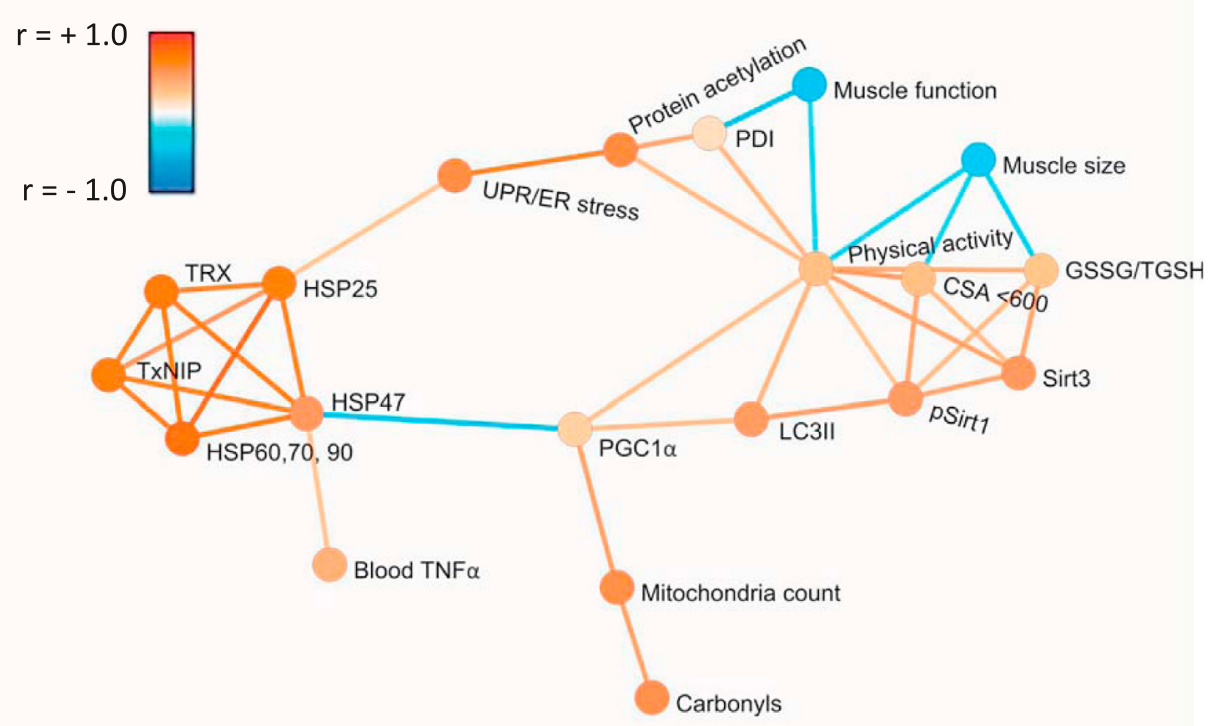

B
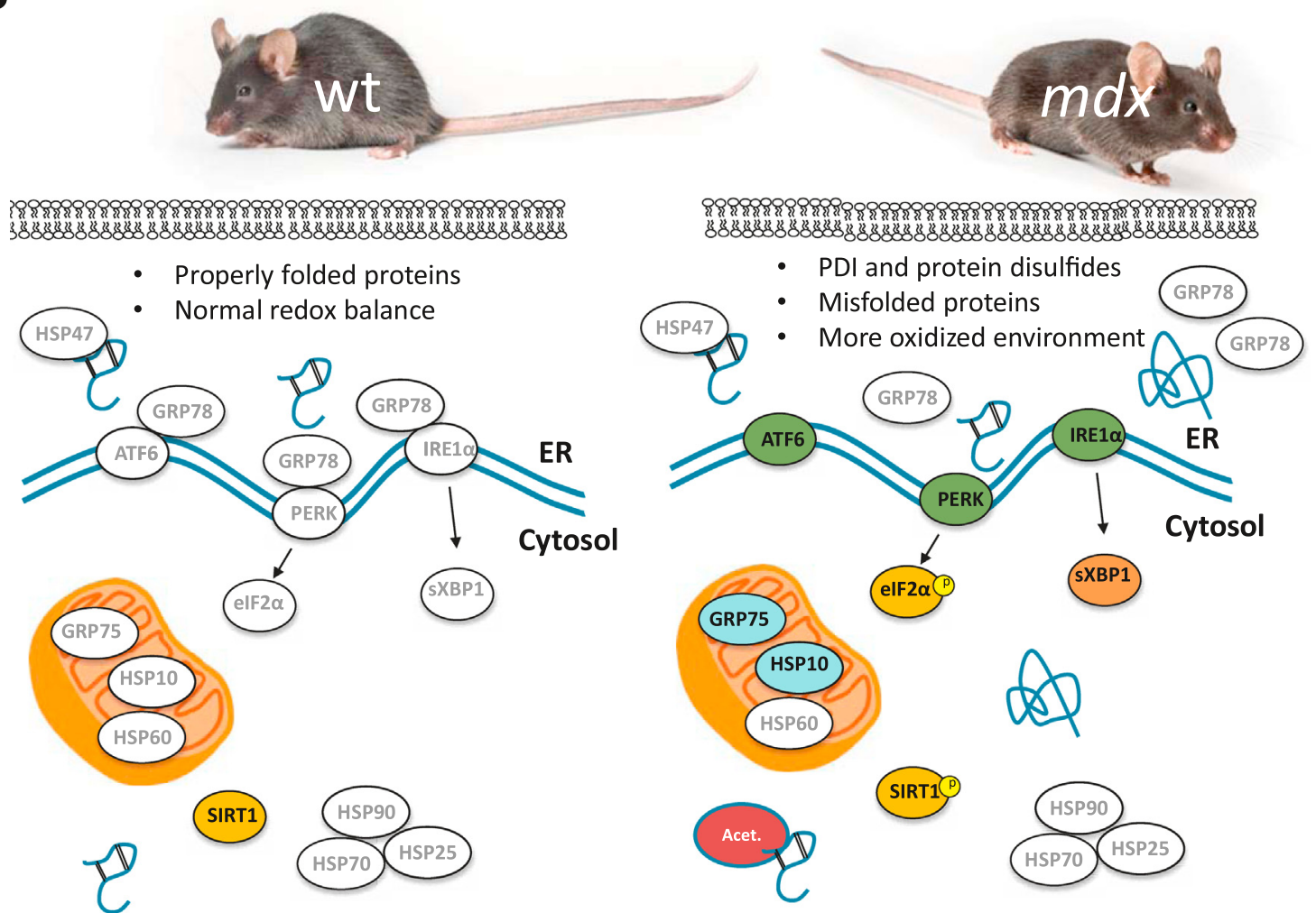

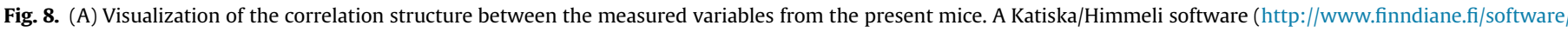

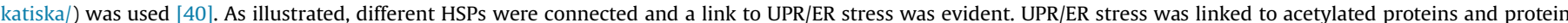

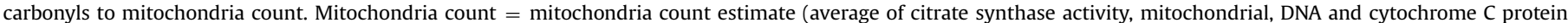

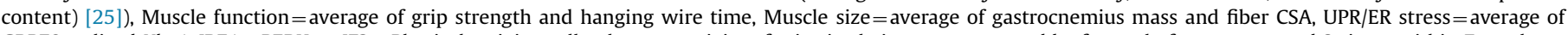

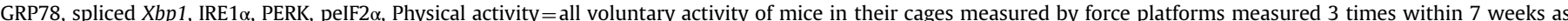

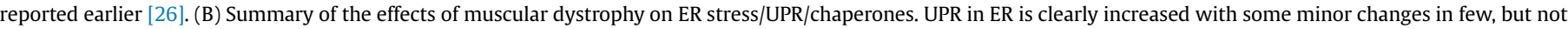
most mitochondrial, but not cytosolic chaperones. Upregulation in $m d x$ vs wild-type control are shown as bolded and in color and no change is shown as gray color.

skeletal muscle. Of these complex processes we focused specifically on proteostasis pathways of ER stress and the UPR, which consists of three canonical branches (PERK, IRE1 $\alpha$ and ATF6).
Notably, most of the measured components of the three canonical branches (IRE1 $\alpha$ protein level, spliced Xbp1 mRNA, PERK, p-eIF2 $\alpha$ and total eIF $2 \alpha$, and Atf6 mRNA ) in skeletal muscle were greater in 
$m d x$ mice compared to wild-type healthy controls. Although a recent report showed increased GRP78/BiP and CHOP proteins in muscle of $m d x$ mice and that ER stress-related caspase activity and apoptosis contributes to $m d x$ pathology [15], this is the first study to provide insight into all three canonical pathways of UPR activation in conjunction with measures of oxidative stress and heat shock protein defense. Notably, the importance of ER stress to the pathology of $m d x$ mice is consistent with other dystrophy studies reporting ER stress in sporadic inclusion body myositis (s-IBM) [41] and tibial muscular dystrophy (TMD) [42]. Running and AcvR2B ligand blocking do not improve or further deteriorate proteostasis in $m d x$ mice, but rather seem to impart mostly neutral effect.

Altered redox balance in the ER has been shown to induce ER stress, which in turn induces the production of ROS in the ER and mitochondria [6]. Oxidative protein folding in the ER has been shown to be a major source of oxidative stress, particularly during ER stress [6]. We detected an increased protein expression of PDI along with a markedly induced gene set of disulfide bond formation in $m d x$ muscle. These alterations in addition to expansion of the protein folding machinery may result from an elevated muscle protein synthesis previously observed in $m d x$ muscle [43]. PDI, an oxidoreductase that belongs to the TRX family, assists the oxidative folding of polypeptides into functional proteins by catalyzing the disulfide bond formation between cysteine residues to stabilize tertiary and quaternary structures [44]. According to microarray data, $m d x$ muscle showed an upregulation in the response of a gene set related to glutathione metabolism possibly contributing to UPR and increased oxidized glutathione (GSSG) levels. The glutathione and thioredoxin superfamilies are the most abundant endogenous thiol antioxidants that maintain redox homeostasis and facilitate correct oxidative protein folding, which involve thiol-disulfide exchange reactions [45]. Several ER-resident glutathione and thioredoxin-dependent peroxidases, including peroxiredoxins and certain isoforms of GPX (i.e., GPX 7 and GPX8) play a critical role in oxidative protein folding [44]. We did not observe any changes in thioredoxin, GSH levels, or GPX activity in $m d x$ mice.

In addition to the UPR in ER (UPR $\left.\mathrm{ER}_{\mathrm{ER}}\right)$, the cytosolic heat shock response and mitochondrial UPR $\left(\mathrm{UPR}_{\mathrm{mt}}\right)$ were investigated. An association between HSPs with UPR/ER stress was evident in correlation-based network analyses indicating the close association of UPR and stress protein responses. This observation is also in agreement with a previous report which showed that increased skeletal muscle HSP72 expression preserves muscle function and slows the progression of severe muscular dystrophy in $\mathrm{mdx}$ mice [46]. Moreover, HSP72 provides protection against ER stress by enhancing IRE1 $\alpha / \mathrm{XBP} 1$ signaling and attenuating ER stress-induced apoptosis [47]. In addition to HSPs, a mitochondrial unfolded protein response $\left(\mathrm{UPR}_{\mathrm{mt}}\right)$ was recently discovered as an adaptation to deficiencies in proteostasis [13]. Unlike ER stress and $\mathrm{UPR}_{\mathrm{ER}}$, no systematic changes in heat shock response/adaptation or $\mathrm{UPR}_{\mathrm{mt}}$ was noticed in $m d x$ mice at the age of $\sim 14$ weeks except slightly increased protein contents of HSP10 and GRP75. Intriguingly, $m d x$ mice showed greater levels of acetylated protein lysine residues. This is interesting because protein hyper-acetylation can be associated with many pathological states [48]. Moreover, because lysine residues can have many different posttranslational modifications, increased acetylation may compete with other posttranslational modifiers [49]. Collectively, these results demonstrate a clear increase in $\mathrm{UPR}_{\mathrm{ER}}$ in dystrophic $m d x$ mice that is accompanied by increases in some indices of oxidative stress and redox regulation including GSSG levels and lysine acetylated proteome, but overall only minor changes in heat shock response/ adaptation and $\mathrm{UPR}_{\mathrm{mt}}$.
An objective of this study was to also address whether two different, but often investigated treatment options including physical exercise and/or blocking myostatin/activins would improve the status of these pathways in skeletal muscle of $m d x$ mice. Administration of sAcvR2B-Fc to block myostatin/activins increased protein expression levels of GRP78 and TxNIP, independent of exercise. GRP78 is an ER-located molecular chaperone belonging to the HSP70 family that is involved in many ERrelated cellular processes including sensing ER stress, inducing UPR, the translocation of newly synthesized polypeptides across the ER membrane, facilitation of protein folding, targeting misfolded proteins for degradation and regulation of calcium homeostasis (for a review see [50]). Although markers of $U_{P R}$ were unchanged by sAcvR2B-Fc, an increase in GRP78 expression is consistent with a recent study wherein overexpression of decorin, an inhibitor of myostatin [51], increased ER-marker genes including GRP78 in duck muscle cells [52]. Conversely, TxNIP inhibits the thioredoxin system, which is a key antioxidant system that protects cells from oxidative stress through its disulfide reductase activity [53]. It was previously shown that ER stress increases TxNIP levels through induction of IRE1 $\alpha$ activity [39]. Interestingly, in the present study GRP78 was strongly associated with TxNIP, a mediator of ER stress-induced inflammation and a protein linking oxidative stress, ER stress and UPR pathways [39]. GRP78 is significantly upregulated after 2 weeks of sAcvR2B-Fc administration, but not yet after single injection (1-2 days) (Hentilä et al. unpublished data) when protein synthesis is acutely already increased [19]. This suggests that the level of disruption to ER homeostasis through increased amounts of newly synthesized proteins by blocking AcvR2B ligands may not be severe enough to trigger a $U P R_{E R}$ response.

HSP levels were not significantly affected by the $m d x$ phenotype, nor were levels changed in response to exercise or sAcvR2BFc treatment in $m d x$ mice. A lack of a well-established effect of regular exercise on increasing HSP levels in $m d x$ muscle suggests the presence of an ameliorated stress protein response and disrupted proteostasis in dystrophic muscle. This assumption is in agreement with previous studies showing that the various disease models which may interfere with protein synthesis also blunt HSP responses to physical exercise [54].

Protein carbonyls can be used as an outcome marker of oxidative damage to skeletal muscle proteins. Voluntary running in combination with sAcvR2B-Fc increased protein carbonyl levels. In addition, protein carbonyl levels showed a strong, positive correlation with activity index in the sAcvR2B-Fc injected mice. These results were corroborated by observations showing that voluntary running also increased GSSG, which is also correlated with protein carbonyl levels in SAcvR2B injected mice (Fig. S8). Even if exercise training has been shown to increase the endogenous anti-oxidative capacity in healthy organisms [4], no consistent effects of exercise on the endogenous antioxidant markers (except glutathione metabolism gene set in microarray data) were observed in the present study. Thus, it seems that running alone, and particularly in combination with sAcvR2B-Fc was not completely tolerable and shifted the redox-balance of the functional dystrophin deficient skeletal muscle to more oxidizing direction. Previously, increased oxidative stress was reported after 4 weeks of running in $m d x$ mice [55]. However, decreased markers of oxidative stress in $m d x$ mice has also been reported after 8 weeks of very low-intensity treadmill running [9] and after 4 weeks of low intensity swimming [10]. Differences in the age of animals, time point of animal euthanization following the last bout of exercise, exercise mode, intensity and volume, and in the basal redox status of $m d x$ mice may explain these results.

In addition to elevating protein carbonyls, running further increased lysine acetylated proteins in $m d x$ mice. Based on these 
findings it is tempting to suggest that the lack of functional dystrophin protein in skeletal muscle cells of $m d x$ mice leads to hyperacetylation of proteins that becomes exacerbated when additional stress (e.g., wheel running) is added. However, the significance of this observation to the pathophysiology of DMD can only be speculated and needs to be studied further in the future. Running independently, and in combination with sAcvR2B-Fc did not exert significant effects on protein folding gene set, PDI protein expression, or other ER stress or UPR markers. Thus, low intensity voluntary running independently or combined with AcvR2B ligand blocking does not increase ER stress or UPR in $m d x$ mice despite the elevated oxidative stress.

Increased muscle mass by SAcvR2B-Fc was not the result of a statistically significant increase in muscle fiber size, nor was it associated with grip strength. Our muscle strength finding using sAcvR2B-Fc is in agreement with others [20,23], and muscle fiber size by some [23], but not all studies [20]. The reason for this lack of change is unknown, but may be explained by changes in proteostasis in the present study and eventually in muscle quality shown previously in long-term AcvR2B ligand blocking experiment [23] and in myostatin knock-out mice [56], possibly together with altered calcium signaling [57].

Exercise shifted the muscle fiber distribution towards smaller fibers, which may explain why strength endurance was not improved by exercise, although aerobic capacity per volume of muscle mass was increased as reported earlier [25]. Exercise has well-known positive effects on health and also voluntary wheel running can improve skeletal muscle function of $m d x$ mice at least in some muscles $[58,59]$. However, some studies have even shown that certain markers are negatively altered by exercise in $m d x$ mice, including e.g. calcium homeostasis if the intensity of the exercise is high $[55,60]$. Clearly, more research is needed on the dose and type of exercise in dystrophic muscle. Thus, although positive effects of exercise on markers of oxidative capacity was reported earlier [25,26], it can be speculated that partially due to increased oxidative stress, no positive effects was seen in muscle endurance or in muscle histology.

Sirtuins are proteins involved in many important processes, including aerobic metabolism, redox regulation as well as UPR $[61,62]$. Increased phosphorylation of SIRT1 at ser ${ }^{46}$ and decreased total SIRT1 was observed in $m d x$ mice when compared to wildtype mice. Moreover, voluntary wheel running independently, and in combination with sAcvR2B-Fc increased the phosphorylation of SIRT1. This coincided with increased protein carbonyls and oxidized glutathione. Previously, Chalkiadaki et al. [38] showed no difference in SIRT1 protein and mRNA expression between wildtype and $m d x$ mice (age 10-12 weeks). This is in contrast with our results and Hourde et al. [58] that reported lower mRNA expression levels of SIRT1 in $m d x$ mice that are increased following 4 months of voluntary wheel running. The effects of the altered phosphorylation of SIRT1 at Ser ${ }^{46 / 47}$ on the activity of the protein are unclear. However, the interventions that increase the enzymatic activity of SIRT1 were suggested to be beneficial for muscular dystrophies [38,63]. On the other hand, even if the increased phosphorylation of SIRT1 at $\operatorname{ser}^{46}$ caused by exercise alone or in combination with sAcvR2B-Fc would improve redox regulation, the outcome of the running combined with the sAcvR2B-Fc was a greater amount of protein carbonyls and increased level of oxidized glutathione that are indicators of elevated levels of oxidative stress and damage.

\section{Conclusions}

Lack of functional dystrophin protein resulted in altered redox regulation, activation of UPR response in ER and increased lysine acetylated proteome in 14-week-old $m d x$ mice. These processes may contribute to the pathophysiology of Duchenne muscular dystrophy. However, mitochondrial UPR or heat shock response/ adaptation were not consistently altered, thus the muscle proteostasis of $m d x$ mice at the age of 14 weeks is not totally dysfunctional. Apart from the observation that sAcvR2B-Fc administration increased protein expression levels of GRP78/BiP and TxNIP, running and activin receptor IIB ligand blocking did not exert a systematic effect on ER stress, UPR or heat shock proteins. A marginal oxidative stress resulting from voluntary wheel running alone or in combination with sAcvR2B-Fc administration does not further compromise the proteostasis of $m d x$ mice but has rather neutral effect. Thus, these treatments may be utilized in conjunction with more direct dystrophin restoration approaches in an effort to restore dysfunctional proteostasis in muscular dystrophy.

\section{Competing interests}

No conflicts of interest, financial or otherwise, are declared by the authors.

\section{Author contributions}

$\mathrm{JJH}, \mathrm{HK}$ and OR designed the original study, while the present study were mainly designed by $\mathrm{JJH}, \mathrm{JH}$ and $\mathrm{MA}$. JJH and BMO carried out the in vivo experiments. MS assisted in the in vivo experiments and isolated muscles. $\mathrm{JJH}$ and $\mathrm{MA}$ drafted the manuscript with the help from JH and $\mathrm{KCD}$. JJH, JH, MA, AK and BMO carried out the analyses. JJH, UMK, HK, KGP and RA were involved in the microarray analysis. OR prepared sAcvR2B-Fc used in the study. All authors read and approved the final manuscript.

\section{Funding}

This work was supported by Academy of Finland (Decision no. 137787 and no. 275922 to JJH and decision no. 134117 to RA) and the Finnish Cultural Foundation (HA) and Paulo Foundation (HK).

\section{Data availability}

The complete data set is publicly available in the NCBI Gene Expression Omnibus (http://www.ncbi.nlm.nih.gov/geo/; accession no. GSE52766).

\section{Acknowledgements}

We would like to thank Mika Silvennoinen, Tuuli Nissinen, Hongqiang Ma, Kaisa-Leena Tulla, Mervi Matero, Juho Hyödynmaa, Risto Puurtinen, Aila Ollikainen, Janne Saarela, Sanna Lensu, Eliisa Kiukkanen, Mia Horttanainen and Taina Vihavainen for their help. sXbp1 primers were a gift from Dr Maarit Lehti.

\section{Appendix A. Supporting information}

Supplementary data associated with this article can be found in the online version at http://dx.doi.org/10.1016/j.freeradbiomed. 2016.08.017. 


\section{References}

[1] M. Koenig, E.P. Hoffman, C.J. Bertelson, A.P. Monaco, C. Feener, L.M. Kunkel, Complete cloning of the duchenne muscular dystrophy (DMD) cDNA and preliminary genomic organization of the DMD Gene in Normal and Affected Individuals, Cell 50 (1987) 509-517.

[2] J.G. Tidball, M. Wehling-Henricks, The role of free radicals in the pathophysiology of muscular dystrophy, J. Appl. Physiol. (1985) 102 (2007) 1677-1686.

[3] C.L. Bladen, D. Salgado, S. Monges, M.E. Foncuberta, K. Kekou, K. Kosma, H. Dawkins, L. Lamont, A.J. Roy, T. Chamova, V. Guergueltcheva, S. Chan, L. Korngut, C. Campbell, Y. Dai, J. Wang, N. Barisic, P. Brabec, J. Lahdetie, M. C. Walter, O. Schreiber-Katz, V. Karcagi, M. Garami, V. Viswanathan, F. Bayat, F. Buccella, E. Kimura, Z. Koeks, J.C. van den Bergen, M. Rodrigues, R. Roxburgh, A. Lusakowska, A. Kostera-Pruszczyk, J. Zimowski, R. Santos, E. Neagu, S. Artemieva, V.M. Rasic, D. Vojinovic, M. Posada, C. Bloetzer, P.Y. Jeannet, F. Joncourt, J. Diaz-Manera, E. Gallardo, A.A. Karaduman, H. Topaloglu, R. El Sherif, A. Stringer, A.V. Shatillo, A.S. Martin, H.L. Peay, M.I. Bellgard, J. Kirschner, K.M. Flanigan, V. Straub, K. Bushby, J. Verschuuren, A. AartsmaRus, C. Beroud, H. Lochmuller, The TREAT-NMD DMD global database: analysis of more than 7000 duchenne muscular dystrophy mutations, Hum. Mutat. 36 (2015) 395-402.

[4] Z. Radak, Z. Zhao, E. Koltai, H. Ohno, M. Atalay, Oxygen consumption and usage during physical exercise: the balance between oxidative stress and ROS-dependent adaptive signaling, Antioxid. Redox Signal. 18 (2013) 1208-1246.

[5] D.P. Jones, Redefining oxidative stress, Antioxid. Redox Signal. 8 (2006) $1865-1879$.

[6] S.S. Cao, R.J. Kaufman, Endoplasmic reticulum stress and oxidative stress in cell fate decision and human disease, Antioxid. Redox Signal. 21 (2014) 396-413.

[7] V. Ljubicic, M. Burt, B.J. Jasmin, The therapeutic potential of skeletal muscle plasticity in duchenne muscular dystrophy: phenotypic modifiers as pharmacologic targets, FASEB J. 28 (2014) 548-568.

[8] M. Sander, B. Chavoshan, S.A. Harris, S.T. Iannaccone, J.T. Stull, G.D. Thomas, R. G. Victor, Functional muscle ischemia in neuronal nitric oxide synthase-deficient skeletal muscle of children with duchenne muscular dystrophy, Proc. Natl. Acad. Sci. USA 97 (2000) 13818-13823.

[9] J.J. Kaczor, J.E. Hall, E. Payne, M.A. Tarnopolsky, Low intensity training decreases markers of oxidative stress in skeletal muscle of mdx mice, Free Radic. Biol. Med. 43 (2007) 145-154.

[10] J. Hyzewicz, J. Tanihata, M. Kuraoka, N. Ito, Y. Miyagoe-Suzuki, S. Takeda, Low intensity training of mdx mice reduces carbonylation and increases expression levels of proteins involved in energy metabolism and muscle contraction, Free Radic. Biol. Med. 82 (2015) 122-136.

[11] J.L. Marshall, J. Holmberg, E. Chou, A.C. Ocampo, J. Oh, J. Lee, A.K. Peter, P. T. Martin, R.H. Crosbie-Watson, Sarcospan-dependent akt activation is required for utrophin expression and muscle regeneration, J. Cell Biol. 197 (2012) 1009-1027.

[12] C. Hetz, E. Chevet, S.A. Oakes, Proteostasis control by the unfolded protein response, Nat. Cell Biol. 17 (2015) 829-838.

[13] V. Jovaisaite, L. Mouchiroud, J. Auwerx, The mitochondrial unfolded protein response, a conserved stress response pathway with implications in health and disease, J. Exp. Biol. 217 (2014) 137-143.

[14] Y. Liu, A. Chang, Heat shock response relieves ER stress, EMBO J. 27 (2008) 1049-1059.

[15] C. Moorwood, E.R. Barton, Caspase-12 ablation preserves muscle function in the mdx mouse, Hum. Mol. Genet. 23 (2014) 5325-5341.

[16] A.C. McPherron, A.M. Lawler, S.J. Lee, Regulation of skeletal muscle mass in mice by a new TGF-beta superfamily member, Nature 387 (1997) 83-90.

[17] J.L. Chen, K.L. Walton, C.E. Winbanks, K.T. Murphy, R.E. Thomson, Y. Makanji, H. Qian, G.S. Lynch, C.A. Harrison, P. Gregorevic, Elevated expression of activins promotes muscle wasting and cachexia, FASEB J. 28 (2014) 1711-1723.

[18] E.E. Pistilli, S. Bogdanovich, M.D. Goncalves, R.S. Ahima, J. Lachey, J. Seehra, T. Khurana, Targeting the activin type IIB receptor to improve muscle mass and function in the mdx mouse model of duchenne muscular dystrophy, Am. J. Pathol. 178 (2011) 1287-1297.

[19] J.J. Hulmi, B.M. Oliveira, M. Silvennoinen, W.M. Hoogaars, H. Ma, P. Pierre, A. Pasternack, H. Kainulainen, O. Ritvos, Muscle protein synthesis, mTORC1/ MAPK/hippo signaling, and capillary density are altered by blocking of myostatin and activins, Am. J. Physiol. Endocrinol. Metab. 304 (2013) E41-E50.

[20] W.M. Hoogaars, E. Mouisel, A. Pasternack, J.J. Hulmi, K. Relizani, M. Schuelke E. Schirwis, L. Garcia, O. Ritvos, A. Ferry, P.A. 't Hoen, H. Amthor, Combined effect of AAV-U7-induced dystrophin exon skipping and soluble activin type IIB receptor in mdx mice, Hum. Gene Ther. 23 (2012) 1269-1279.

[21] S.J. Lee, L.A. Reed, M.V. Davies, S. Girgenrath, M.E. Goad, K.N. Tomkinson, J. F. Wright, C. Barker, G. Ehrmantraut, J. Holmstrom, B. Trowell, B. Gertz, M. S. Jiang, S.M. Sebald, M. Matzuk, E. Li, L.F. Liang, E. Quattlebaum, R.L. Stotish, N M. Wolfman, Regulation of muscle growth by multiple ligands signaling through activin type II receptors, Proc. Natl. Acad. Sci. USA 102 (2005) 18117-18122.

[22] K.J. Morine, L.T. Bish, J.T. Selsby, J.A. Gazzara, K. Pendrak, M.M. Sleeper, E. R. Barton, S.J. Lee, H.L. Sweeney, Activin IIB receptor blockade attenuates dystrophic pathology in a mouse model of duchenne muscular dystrophy, Muscle Nerve 42 (2010) 722-730.

[23] K. Relizani, E. Mouisel, B. Giannesini, C. Hourde, K. Patel, S. Morales Gonzalez, K. Julich, A. Vignaud, F. Pietri-Rouxel, D. Fortin, L. Garcia, S. Blot, O. Ritvos, D. Bendahan, A. Ferry, R. Ventura-Clapier, M. Schuelke, H. Amthor, Blockade of
ActRIIB signaling triggers muscle fatigability and metabolic myopathy, Mol. Ther. 22 (2014) 1423-1433.

[24] J.A. Timmons, O. Larsson, E. Jansson, H. Fischer, T. Gustafsson, P.L. Greenhaff, J. Ridden, J. Rachman, M. Peyrard-Janvid, C. Wahlestedt, C.J. Sundberg Human muscle gene expression responses to endurance training provide a novel perspective on duchenne muscular dystrophy, FASEB J. 19 (2005) 750-760.

[25] J.J. Hulmi, B.M. Oliveira, M. Silvennoinen, W.M. Hoogaars, A. Pasternack, H. Kainulainen, O. Ritvos, Exercise restores decreased physical activity levels and increases markers of autophagy and oxidative capacity in myostatin/activin-blocked mdx mice, Am. J. Physiol. Endocrinol. Metab. 305 (2013) E171-E182.

[26] H. Kainulainen, K.G. Papaioannou, M. Silvennoinen, R. Autio, J. Saarela, B. M. Oliveira, M. Nyqvist, A. Pasternack, P.A. 't Hoen, U.M. Kujala, O. Ritvos, J. J. Hulmi, Myostatin/activin blocking combined with exercise reconditions skeletal muscle expression profile of mdx mice, Mol. Cell. Endocrinol. 399 (2015) 131-142.

[27] J. Wu, J.L. Ruas, J.L. Estall, K.A. Rasbach, J.H. Choi, L. Ye, P. Bostrom, H.M. Tyra, R. W. Crawford, K.P. Campbell, D.T. Rutkowski, R.J. Kaufman, B.M. Spiegelman, The unfolded protein response mediates adaptation to exercise in skeletal muscle through a PGC-1alpha/ATF6alpha complex, Cell. Metab. 13 (2011) 160-169.

[28] S. Kinnunen, S. Hyyppa, J. Lappalainen, N. Oksala, M. Venojarvi, C. Nakao, O. Hanninen, C.K. Sen, M. Atalay, Exercise-induced oxidative stress and muscle stress protein responses in trotters, Eur. J. Appl. Physiol. 93 (2005) 496-501.

[29] G.M. Gordillo, M. Atalay, S. Roy, C.K. Sen, Hemangioma model for in vivo angiogenesis: inducible oxidative stress and MCP-1 expression in EOMA cells, Methods Enzymol. 352 (2002) 422-432.

[30] E. Shacter, J.A. Williams, M. Lim, R.L. Levine, Differential susceptibility of plasma proteins to oxidative modification: examination by western blot immunoassay, Free Radic. Biol. Med. 17 (1994) 429-437.

[31] Z. Lappalainen, J. Lappalainen, N.K. Oksala, D.E. Laaksonen, S. Khanna, C.K. Sen, M. Atalay, Diabetes impairs exercise training-associated thioredoxin response and glutathione status in rat brain, J. Appl. Physiol. (1985) 106 (2009) 461-467.

[32] C.K. Sen, E. Marin, M. Kretzschmar, O. Hanninen, Skeletal muscle and liver glutathione homeostasis in response to training, exercise, and immobilization, J. Appl. Physiol. (1985) 73 (1992) 1265-1272.

[33] N. Lambert, R.B. Freedman, Kinetics and specificity of homogeneous protein disulphide-isomerase in protein disulphide isomerization and in thiol-protein-disulphide oxidoreduction, Biochem. J. 213 (1983) 235-243.

[34] M.A. Kallio, J.T. Tuimala, T. Hupponen, P. Klemela, M. Gentile, I. Scheinin, M. Koski, J. Kaki, E.I. Korpelainen, Chipster: user-friendly analysis software for microarray and other high-throughput data, BMC Genom. 12 (2011), 5072164-12-507.

[35] G.K. Smyth, Linear models and empirical bayes methods for assessing differential expression in microarray experiments, Stat. Appl. Genet. Mol. Biol. 3 (2004), Article3.

[36] G. Dennis, Jr, B.T. Sherman, D.A. Hosack, J. Yang, W. Gao, H.C. Lane, R. A. Lempicki, DAVID: database for annotation, visualization, and integrated discovery, Genome Biol. 4 (2003) P3.

[37] A. Subramanian, P. Tamayo, V.K. Mootha, S. Mukherjee, B.L. Ebert, M.A. Gillette, A. Paulovich, S.L. Pomeroy, T.R. Golub, E.S. Lander, J.P. Mesirov, Gene set enrichment analysis: a knowledge-based approach for interpreting genomewide expression profiles, Proc. Natl. Acad. Sci. USA 102 (2005) 15545-15550.

[38] A. Chalkiadaki, M. Igarashi, A.S. Nasamu, J. Knezevic, L. Guarente, Musclespecific SIRT1 gain-of-function increases slow-twitch fibers and ameliorates pathophysiology in a mouse model of duchenne muscular dystrophy, PLoS Genet 10 (2014) e1004490.

[39] C.M. Oslowski, T. Hara, B. O'Sullivan-Murphy, K. Kanekura, S. Lu, M. Hara, S. Ishigaki, L.J. Zhu, E. Hayashi, S.T. Hui, D. Greiner, R.J. Kaufman, R. Bortell, F. Urano, Thioredoxin-interacting protein mediates ER stress-induced beta cell death through initiation of the inflammasome, Cell. Metab. 16 (2012) 265-273.

[40] V.P. Makinen, C. Forsblom, L.M. Thorn, J. Waden, K. Kaski, M. Ala-Korpela, P. H. Groop, Network of vascular diseases, death and biochemical characteristics in a set of 4197 patients with type 1 diabetes (the FinnDiane study), Cardiovasc. Diabetol. 8 (2009), 54-2840-8-54.

[41] G. Vattemi, W.K. Engel, J. McFerrin, V. Askanas, Endoplasmic reticulum stress and unfolded protein response in inclusion body myositis muscle, Am. J. Pathol. 164 (2004) 1-7.

[42] M. Screen, O. Raheem, J. Holmlund-Hampf, P.H. Jonson, S. Huovinen, P. Hackman, B. Udd, Gene expression profiling in tibial muscular dystrophy reveals unfolded protein response and altered autophagy, PLoS One 9 (2014) e90819.

[43] P.A. MacLennan, R.H. Edwards, Protein turnover is elevated in muscle of mdx mice in vivo, Biochem. J. 268 (1990) 795-797.

[44] J.J. Galligan, D.R. Petersen, The human protein disulfide isomerase gene family, Hum. Genom. 6 (2012), 6-7364-6-6.

[45] S. Lee, S. Min Kim, J. Dotimas, L. Li, E.P. Feener, S. Baldus, R.B. Myers, W. A. Chutkow, P. Patwari, J. Yoshioka, R.T. Lee, Thioredoxin-interacting protein regulates protein disulfide isomerases and endoplasmic reticulum stress, EMBO Mol. Med. 6 (2014) 732-743.

[46] S.M. Gehrig, C. van der Poel, T.A. Sayer, J.D. Schertzer, D.C. Henstridge, J E. Church, S. Lamon, A.P. Russell, K.E. Davies, M.A. Febbraio, G.S. Lynch, Hsp72 preserves muscle function and slows progression of severe muscular dystrophy, Nature 484 (2012) 394-398. 
[47] S. Gupta, A. Deepti, S. Deegan, F. Lisbona, C. Hetz, A. Samali, HSP72 protects cells from ER stress-induced apoptosis via enhancement of IRE1alpha-XBP1 signaling through a physical interaction e1000410, PLoS Biol. 8 (2010).

[48] M.D. Hirschey, T. Shimazu, E. Jing, C.A. Grueter, A.M. Collins, B. Aouizerat A. Stancakova, E. Goetzman, M.M. Lam, B. Schwer, R.D. Stevens, M. J. Muehlbauer, S. Kakar, N.M. Bass, J. Kuusisto, M. Laakso, F.W. Alt, C. B. Newgard, R.V. Farese Jr, C.R. Kahn, E. Verdin, SIRT3 deficiency and mitochondrial protein hyperacetylation accelerate the development of the metabolic syndrome, Mol. Cell 44 (2011) 177-190.

[49] A. Nakamura, K. Kawakami, F. Kametani, H. Nakamoto, S. Goto, Biological significance of protein modifications in aging and calorie restriction, Ann. N.Y. Acad. Sci. 1197 (2010) 33-39.

[50] M. Wang, S. Wey, Y. Zhang, R. Ye, A.S. Lee, Role of the unfolded protein response regulator GRP78/BiP in development, cancer, and neurological disorders, Antioxid. Redox Signal. 11 (2009) 2307-2316.

[51] T. Miura, Y. Kishioka, J. Wakamatsu, A. Hattori, A. Hennebry, C.J. Berry, M. Sharma, R. Kambadur, T. Nishimura, Decorin binds myostatin and modulates its activity to muscle cells, Biochem. Biophys. Res. Commun. 340 (2006) 675-680.

[52] L. Sun, K. Lu, H. Liu, H. Wang, X. Li, C. Yang, L. Li, J. Wang, The effects of endoplasmic reticulum stress response on duck decorin stimulate myotube hypertrophy in myoblasts, Mol. Cell. Biochem. 377 (2013) 151-161.

[53] E. Yoshihara, S. Masaki, Y. Matsuo, Z. Chen, H. Tian, J. Yodoi, Thioredoxin/txnip: redoxisome, as a redox switch for the pathogenesis of diseases, Front. Immunol. 4 (2014) 514.

[54] M. Atalay, N.K. Oksala, D.E. Laaksonen, S. Khanna, C. Nakao, J. Lappalainen, S. Roy, O. Hanninen, C.K. Sen, Exercise training modulates heat shock protein response in diabetic rats, J. Appl. Physiol. (1985) 97 (2004) 605-611.

[55] K.E. Schill, A.R. Altenberger, J. Lowe, M., Periasamy, F.A., Villamena, J.A., RafaelFortney, S.T. Devor, Muscle damage, metabolism, \& oxidative stress in mdx mice: impact of aerobic running, Muscle Nerve 54 (2015) 110-117, http:// www.ncbi.nlm.nih.gov/pubmed/26659868.

[56] H. Amthor, R. Macharia, R. Navarrete, M. Schuelke, S.C. Brown, A. Otto, T. Voit F. Muntoni, G. Vrbova, T. Partridge, P. Zammit, L. Bunger, K. Patel, Lack of myostatin results in excessive muscle growth but impaired force generation, Proc. Natl. Acad. Sci. USA 104 (2007) 1835-1840.

[57] D. Bodnar, N. Geyer, O. Ruzsnavszky, T. Olah, B. Hegyi, M. Sztretye, J. Fodor, B. Dienes, A. Balogh, Z. Papp, L. Szabo, G. Muller, L. Csernoch, P. Szentesi, Hypermuscular mice with mutation in the myostatin gene display altered calcium signalling, J. Physiol. 592 (2014) 1353-1365.

[58] C. Hourde, P. Joanne, F. Medja, N. Mougenot, A. Jacquet, E. Mouisel, A. Pannerec, S. Hatem, G. Butler-Browne, O. Agbulut, A. Ferry, Voluntary physical activity protects from susceptibility to skeletal muscle contractioninduced injury but worsens heart function in mdx mice, Am. J. Pathol. 182 (2013) 1509-1518.

[59] K.A. Baltgalvis, J.A. Call, G.D. Cochrane, R.C. Laker, Z. Yan, D.A. Lowe, Exercise training improves plantar flexor muscle function in mdx mice, Med. Sci. Sports Exerc. 44 (2012) 1671-1679.

[60] B. Fraysse, A. Liantonio, M. Cetrone, R. Burdi, S. Pierno, A. Frigeri, M. Pisoni, C. Camerino, A. De Luca, The alteration of calcium homeostasis in adult dystrophic mdx muscle fibers is worsened by a chronic exercise in vivo, Neurobiol. Dis. 17 (2004) 144-154.

[61] L. Papa, D. Germain, SirT3 regulates the mitochondrial unfolded protein response, Mol. Cell. Biol. 34 (2014) 699-710.

[62] R.H. Houtkooper, E. Pirinen, J. Auwerx, Sirtuins as regulators of metabolism and healthspan, Nat. Rev. Mol. Cell Biol. 13 (2012) 225-238.

[63] Y.S. Hori, A. Kuno, R. Hosoda, M. Tanno, T. Miura, K. Shimamoto, Y. Horio, Resveratrol ameliorates muscular pathology in the dystrophic mdx mouse, a model for duchenne muscular dystrophy, J. Pharmacol. Exp. Ther. 338 (2011) 784-794. 